\title{
Numerical Modeling of 3D Flow Field among a Compound Stilling Basin
}

\author{
Zhao Zhou $(\mathbb{D}$ and Junxing Wang $(\mathbb{D}$ \\ State Key Laboratory of Water Resource and Hydropower Engineering Science, Wuhan University, Wuhan 430072, China \\ Correspondence should be addressed to Zhao Zhou; 1021235166@qq.com
}

Received 8 February 2019; Revised 5 May 2019; Accepted 20 May 2019; Published 12 June 2019

Academic Editor: Yannis Dimakopoulos

Copyright ( 2019 Zhao Zhou and Junxing Wang. This is an open access article distributed under the Creative Commons Attribution License, which permits unrestricted use, distribution, and reproduction in any medium, provided the original work is properly cited.

\begin{abstract}
Due to great velocity gradients among the outgoing flow, it is much common to form large-scale reverse flow with oblique movements outside the conventional separated stilling basin. Aimed at above problems, this paper proposes to remove the longitudinal splitter wall and then physically and numerically investigate the corresponding influence upon the compound stilling basin. The standard $\mathrm{k}-\varepsilon$, renormalization group $\mathrm{k}-\varepsilon$, realizable $\mathrm{k}-\varepsilon$, and large eddy simulation turbulence models are all employed to reveal downstream three-dimensional flow field. Experimental validation of numerical results shows that the renormalization group $\mathrm{k}-\varepsilon$ turbulence model is the most successful in predicting the flow field among the four models. Both methods prove that the removed splitter wall exerts great impact upon downstream stilling basin. In view of the removed splitter wall, discharging inflow would greatly diffuse to form a typical three-dimensional (3D) hydraulic jump with large-scale reverse flow. High energy dissipation region and high turbulent kinetic energy region are both moved upstream. Thus, the velocity decay among the discharging flow in the compound stilling basin is significantly enhanced. Compared to the separated stilling basin, the maximum velocity and average velocity of the outgoing flow, respectively, decrease more than $30 \%$, and $20 \%$ in the compound stilling basin. Additionally, the velocity gradients between the left and the right outgoing flow reduce by over $65 \%$ with turbulent kinetic energy gradients almost down to zero. The outgoing flow from the compound stilling basin becomes much uniform with the phenomenon of obliquely moving flow totally eliminated.
\end{abstract}

\section{Introduction}

As an effective method of energy dissipation, a hydraulic jump is widely applied among the domain of low water head projects, such as ogee weirs and sluice gates [1]. The traditional hydraulic jump is a transition process of a supercritical flow into a subcritical flow on a horizontal and rectangular open channel, among which large-scale transverse vortex would dissipate the carried energy among the flow [2-4]. Currently, some auxiliary energy dissipators, such as baffle blocks, T-shaped piers, and baffle sills, are often arranged above the slab to increase the energy dissipation effect. But some secondary problems (cavitation damages and atomization) may be attendant during the discharging process.

Recently, a new kind of energy dissipation concept (threedimensional (3D) hydraulic jump) has been proposed and applied into low water head domain. Compared to a classic hydraulic jump, the 3D hydraulic jump would not only maintain the traditional transverse vortex of two-dimensional (2D) hydraulic jump, but also force the discharging flow to laterally diffuse to promote mutual impingement, even resulting in vertical vortex with large-scale lateral movements. The investigations about flaring gate pier, expanding hydraulic jump, and symmetric water jets have attained some progress and shown great energy dissipation effect [5-8].

Kordi and Abustan [2] presented the velocity variation of an expanding hydraulic jump in a rectangular horizontal open channel. The results showed that, compared to a classic jump, the postdepth for the expanding hydraulic jump was much smaller and the jump length was slightly longer. Chen et al. [9] experimentally investigated the energy dissipation characteristics of a hydraulic jump after free overfall and proved that the energy dissipation in an expanding channel was much greater than that in a prismatic channel. Omid et al. [6] investigated the hydraulic jump in a gradually expanding 


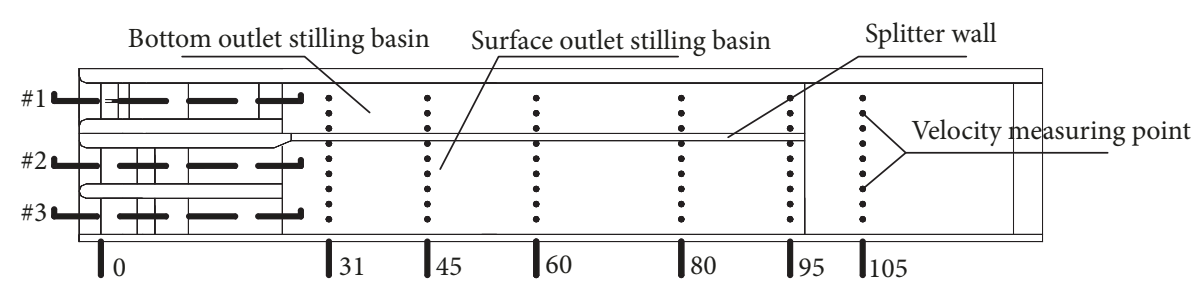

(a) Plane layout

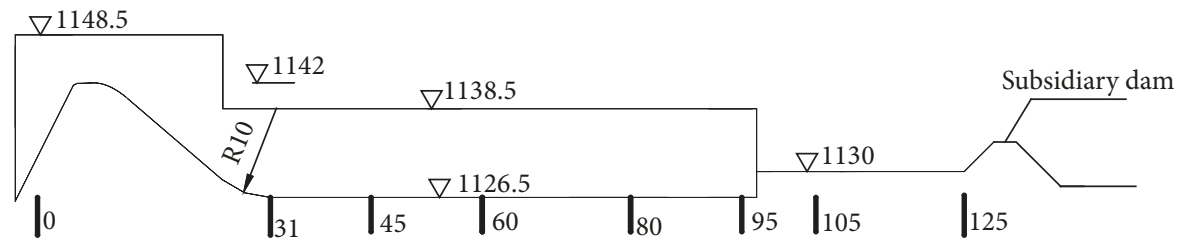

(b) Surface outlet profile (Section 2-2)

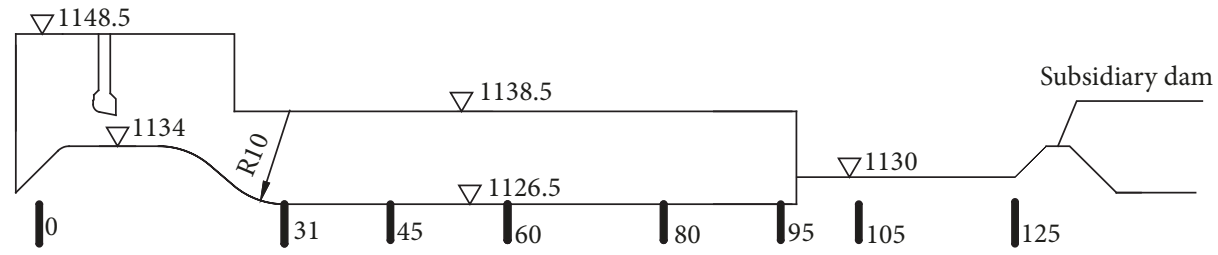

(c) Bottom outlet profile (Section \#1-1)

FIGURE 1: Engineering layout (unit: $m$ ). Notification: each section is uniformly divided with nine points to measure the velocity.

stilling basin of trapezoidal cross section and found that, relative to the rectangular stilling basin, the divergent stilling basin would cause reductions in the sequent depth but increasement in energy loss among the hydraulic jump. Bijankhan and Kouchakzadeh [10] experimentally investigated parallel jets from multiple parallel gate and proved that highly nonuniform velocity was of great importance to determine the head loss through free parallel jets hydraulic jump. Similar descriptions about expanding hydraulic jump can also be found in the literature [11-14].

It can be noticed from the above statements that the expanding hydraulic jump can significantly increase the energy loss and decrease down postdepth. But the precedent investigations are mainly based on the expanding stilling basin with expanding cross section. Such arrangement is much difficult to achieve due to the increased amount of engineering excavation, especially for low head spillways among the alpine valley areas. Almost none of the academic researchers have utilized the conventional arrangement of flood releasing structure in a typical low head projects. In fact, it is quite common that a bottom outlet is closely arranged next to a surface outlet among the typical low head flood releasing structure. Thus, due to structure differences, the bottom outlet and the surface outlet may jointly operate to generate quite different inflows. If such feature can be utilized, a 3D hydraulic jump with much lateral diffusion would also be formed. However, a longitudinal splitter wall would be arranged to divide the downstream region as a bottom outlet stilling basin and a surface outlet stilling basin in the traditional arrangement of stilling basins. Such arrangement is intended to avoid mutual interferences when both outlets are jointly running.
Aimed at the above arrangement, this paper proposes to remove the downstream splitter wall to form a compound stilling basin; thus both outlets can jointly share the downstream stilling basin. In view of the enlarged cross section, the discharging inflow would greatly diffuse to form large-scale reverse flow in the compound stilling basin, consequently enhancing mutual impingement and shear friction among the flow. In the present paper, a physical model is particularly arranged to investigate the influence of splitter wall upon the downstream stilling basin. Furthermore, as a complement, the numerical simulation by employing the standard $\mathrm{k}$ $\varepsilon$ (SKE), renormalization group $\mathrm{k}-\varepsilon$ (RNG), realizable $\mathrm{k}-\varepsilon$ (RKE), and large eddy simulation (LES) turbulence closure models are all conducted to make a mutual comparison to further reveal the $3 \mathrm{D}$ flow field in the compound stilling basin.

\section{Experiment Setup}

Based on a common practical engineering case, the Lotus Temple Hydropower Station in the Gourd River region, Gansu Province, China, is physically modeled at the Hydraulic Model Test Hall of Wuhan University at a geometrical scale of 1:25. As shown in Figure 1, the flood releasing structures are mainly composed of a sluice gate (a bottom outlet) and two overflow weirs (two surface outlets). Much similar to other low head projects, the bottom outlet is closely arranged next to the surface outlets. For convenient description, the outlets are successively described as Outlets $\# 1$, \#2, and \#3 from the left to the right in the current paper and the corresponding axes of each outlet are called as Sections 1-1, 2-2, and 3-3. The elevation of dam top, 
TABLE 1: Running condition for the hydropower station.

\begin{tabular}{lccc}
\hline Condition & Reservoir inflow $\left(\mathrm{m}^{3} \cdot \mathrm{s}^{-1}\right)$ & Upstream water level $(\mathrm{m})$ & Description \\
\hline 1 & 215 & 1147 & Open the bottom outlet and close the surface outlet \\
2 & 226 & 1147 & Close the bottom outlet and open the surface outlet \\
3 & 441 & 1147 & Both open the surface and bottom outlets \\
\hline
\end{tabular}

weir crest, and sluice slab is $1148.5 \mathrm{~m}, 1142 \mathrm{~m}$, and $1134 \mathrm{~m}$, respectively. Referring to the downstream stilling basin slab, the maximum dam height only reaches $22 \mathrm{~m}$. The inlet sizes for each chamber are the same as $5 \mathrm{~m} \times 5 \mathrm{~m}$ (width $\times$ height). Both kinds of outlets adopt the same anti-arc (diameter to be $10 \mathrm{~m}$ ) to connect the horizontal stilling basin and share the same entrance section of $Y=31 \mathrm{~m}(\mathrm{Y}=0 \mathrm{~m}$ means the lateral dam axis and $Y$ directs to the downstream). The dimension of the stilling basin is $66 \mathrm{~m} \times 21 \mathrm{~m} \times 3.5 \mathrm{~m}$ (length $\times$ width $\times$ depth) and the slab elevation is $1126.5 \mathrm{~m}$. A vertical baffle sill of $3.5 \mathrm{~m}$ height is located at the end of the stilling basin and a subsidiary dam is arranged about $28 \mathrm{~m}$ downstream the stilling basin outlet.

In the original design, a splitter wall of $12.5 \mathrm{~m} \times 2 \mathrm{~m}$ (depth $x$ width) is longitudinally arranged in the downstream region, thus dividing the downstream region as the bottom outlet stilling basin and the surface outlet stilling basin (shown in Figure 1(a)). Such arrangement is expected to avoid mutual interference when both kinds of outlets are jointly running. This original design is quite common among the low water head projects.

Like some other hydraulic projects, the main purpose for this hydropower station is to generate electricity and irrigate. Thus, to ensure the normal operation for turbines, the upstream water level should be maintained as stable as $1147 \mathrm{~m}$ (the designed water level). Such requirement is quite common among the practical engineering cases. But due to the randomly varying reservoir inflows, both kinds of outlets may be forced to flexibly operate to meet that requirement in the long time. Thus, as shown in Table 1, a typical dispatching scheme is made to respond to the varying reservoir inflows. The $1^{\text {st }}$ and $2^{\text {nd }}$ conditions are successively the alone operation for the bottom outlet and the surface outlet, respectively. The $3^{\text {rd }}$ condition is the joint operation for both kinds of outlets. It can be noticed that such dispatching scheme can swiftly respond to reservoir inflows.

The whole physical model, about $14 \mathrm{~m} \times 4 \mathrm{~m}$ (length $\times$ width), mainly covers the upstream reservoir region, the dam body-stilling basin region, and the downstream river bed region. A $50 \mathrm{~cm}$ diameter pipeline is arranged to pump water from an underground tank into the upstream reservoir. A valve and an intelligent electromagnetic flow meter (Jiangsu Runyi Instrument Co., ltd, accuracy to be $\pm 0.1 \mathrm{~L} / \mathrm{s}$ ) are both arranged along the pipeline to adjust and record the reservoir inflows. To control the downstream tail water, a tailgate is arranged at the downstream region. In addition, the upstream topography and downstream beaches are all modeled with evenly arranged sectional panels. For clear observation, the dam body is made up of the plexiglass to conform to the prototype curve. Considering the difference between adjacent outlets, a point gauge with an accuracy of $\pm 0.1 \mathrm{~mm}$ is longitudinally arranged along Sections 1-1 and 2-2.

In addition, to validate the influence of splitter wall upon the downstream stilling basin, two different schemes are particularly arranged to investigate mutual differences. Scheme 1 is the original design plan and can be called the separated stilling basin (as shown in Figure 1); Scheme 2 particularly removes the splitter wall and can be called the compound stilling basin.

2.1. Governing Equations. The commercial software Flow 3D is adopted here to simulate the $3 \mathrm{D}$ flow field among the numerical model. Compared to other similar computational fluid dynamics (CFD) software, the Flow 3D is much more convenient for gird generation due to the unique Fractional Area-Volume Obstacle Representation (Favor) technology. The continuity equation and Reynolds Average Navier Stokes (RANS) equations are applied here to numerically model the present case. For an incompressible, Newtonian fluid flow, these equations can be expressed as

$$
\begin{gathered}
\frac{\partial\left(u_{i} A_{i}\right)}{\partial x_{i}}=0 \\
\frac{\partial u_{i}}{\partial t}+\frac{1}{V_{F}}\left(u_{j} A_{j} \frac{\partial u_{i}}{\partial x_{j}}\right)=-\frac{1}{\rho} \frac{\partial p}{\partial x_{i}}+G_{i}+f_{i}
\end{gathered}
$$

where $u_{i}$ are the velocity components in the $X_{i}$ directions in the Cartesian coordinate, $i=1,2$, and $3 ; A_{i}$ and $V_{F}$ respectively represent the fraction area and fraction volume open to the flow in the $X_{i}$ directions; $\mathrm{t}$ is the time; $\rho$ is the density; $p$ is the pressure; $G_{i}$ are the gravitational force in the corresponding $x_{i}$ directions; $f_{i}$ stand for Reynolds stress that can be calculated by a turbulence closure model.

2.2. Turbulence Models. With the development of CFD technology, a variety of turbulence closure models have been proposed and applied into the numerical simulation. In the present study, the standard $\mathrm{k}-\varepsilon$ (SKE) [15], renormalization group (RNG) [16], realizable k- $\varepsilon$ (RKE) [17], and large eddy simulation (LES) [18] turbulence closure models are all adopted to make a mutual comparison with the physical results to figure out more accurate simulation.

The SKE is probably one of the most widely applied twoequation turbulence closure models because of its simplicity and shorter computation time. Assuming the flow to be fully turbulent, the SKE model ignores the influence of molecular viscosity. In addition, it assumes the Reynolds stress should be proportional to the time-average strain at a local point and overlooks the historical effect in the streamwise direction. 


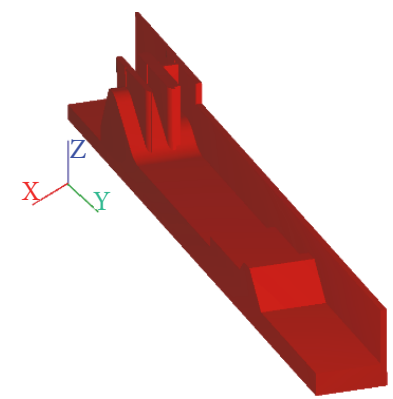

(a) Schematic for 3D solid model

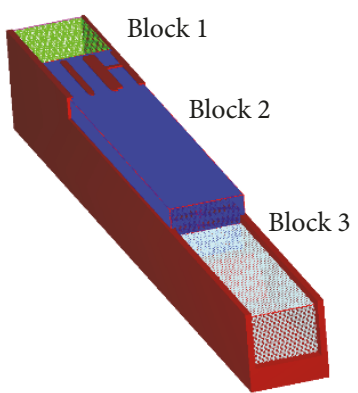

(b) Solid model with mesh

FIGURE 2: Schematic view of the 3D numerical model. Notification: the side wall on the right in Figure 2(a) is particularly overlooked for clear observation.

Thus, the SKE model is only suitable for fully turbulent flow and shows poor accuracies in the separation flow or large curvature flow. Owing to the development of computation fluid dynamic (CFD), many academic researchers have achieved great progress about the model turbulence. Taking the turbulent vortex into account, the RNG model accurately deduces each coefficient of turbulent energy equation (k equation) and turbulent dissipation rating equation ( $\varepsilon$ equation) through renormalization group theories. With better versatility, the RNG model does not need to adjust the coefficient values for a specific flow and acquires high accuracies and reliability. But the RKE model does not regard the coefficient in the turbulent viscosity equation as a constant but related to strain rate. The RKE model has shown great performances among the domain of rotating flow, secondary flow, and boundary layer flow with great pressure gradients. The principal idea about LES model is to accurately capture all the flow motion above a certain scale, thus capturing the coherent structures among the unsteady and nonequilibrium process. Due to the quite huge calculation amount, it can not be widely used in the practical engineering application.

\subsection{Numerical Model Implementation and Grid Generation.} The computational domain should be as similar as possible to the physical model. In consideration of the tiny influence of the retaining dam on both sides upon the discharging flow, the numerical model is slightly simplified for convenience of mesh generalization. As shown in Figure 2, the simplified 3D numerical model is composed of the upstream reservoir, the dam body-stilling basin, and the downstream river bed. The directions of $\mathrm{X}, \mathrm{Y}$, and $\mathrm{Z}$, respectively, direct to the lateral, the longitudinal, and the anti-gravity. The coordinate origin is located at the bottom of the sluice gate (Outlet \#1), just at the intersection point between the lateral and the longitudinal axes.

The 3D model is subdivided as three different blocks in view of velocity gradients in each region, among which Blocks 1,2 , and 3 successively represent the upstream reservoir region, the dam body-stilling basin region, and the downstream river bed region. In view of similar geometric sizes in all directions, the unique gird generation technology of Fractional Area-Volume Obstacle Representation (FAVOR) is adopted to define the numerical model with hexahedral cells.
Due to the sharp variations of hydraulic parameters in the stilling basin, Block 2 is compacted with much finer grids (as shown in Figure 2(b)).

2.4. Initial Boundary Condition. The upstream boundary is located at $50 \mathrm{~m}$ upstream the dam axis to make sure there is a fully developed flow into the reservoir. Correspondingly, the downstream boundary is located at $100 \mathrm{~m}$ downstream the stilling basin to reserve enough room to adjust the outgoing flow. In consideration of the approach velocity into the reservoir, the upstream boundary condition $\left(\mathrm{Y}_{\min }\right)$ is set as stagnation pressure. The downstream boundary $\left(\mathrm{Y}_{\max }\right)$ is set as local static pressure based on downstream tail water. The boundary conditions for both sides $\left(\mathrm{X}_{\min }\right.$ and $\left.\mathrm{X}_{\max }\right)$ and the bottom $\left(Z_{\text {min }}\right)$ are set as common smooth wall. The longitudinal interfaces between adjacent blocks are set symmetry boundary to let the water freely pass. The similar boundary conditions setting for 3D numerical model in the Flow 3D software can be found in Valero's descriptions [19].

2.5. Near Wall Treatment. Usually, all the above mentioned turbulence models are quite accurate and valid only to fully turbulent flows. But near the wall, the flow is almost laminar and the turbulent stress hardly works, especially for the viscous sublayer region $[20,21]$. The traditional turbulence models do not work well here. Currently, there are two different methods (near wall modeling method and wall function method) to solve the problem. Both methods involve a dimensionless distance $\mathrm{y}^{+} \cdot \mathrm{y}^{+}=\mathrm{yv} * / v \cdot \mathrm{V} *$ is the shear velocity; $y$ is the perpendicular distance between the first grid point and the wall; $v$ is the kinematic viscosity of the fluid. The near wall modeling method directly utilizes the low Reynolds number turbulence model with much fine grids near the wall to deduce parameters in the viscous sublayer. It requires that the grid point of the first layer should be arranged within the viscous layer $\left(\mathrm{y}^{+}<1\right)$. The wall function method does not directly deduce the viscous sublayer, but arranges the grid point of first layer within the log law region $\left(30<\mathrm{y}^{+}<\right.$ 200 400) and then relates the viscous layer to the log law region with empirical formulas. Compared with the near wall modeling method, the wall function method does not need to specifically compact the grid near the wall but saves much more computation time with higher efficiency [19, 22-24]. 
TABLE 2: Grid details in each block.

\begin{tabular}{lccccc}
\hline Block & $\begin{array}{c}\text { Grid 1 } \\
\text { Grid size }(\mathrm{m})\end{array}$ & $\begin{array}{c}\text { Grid 2 } \\
\text { Grid size }(\mathrm{m})\end{array}$ & $\begin{array}{c}\text { Grid 3 } \\
\text { Grid size }(\mathrm{m})\end{array}$ & Near wall distance (m) & dimensionless distance y+ \\
\hline Upstream reservoir block & $0.8 \times 0.8 \times 0.8$ & $0.8 \times 0.8 \times 0.8$ & $0.8 \times 0.8 \times 0.8$ & 0.1 & 46.71 \\
Dam body-stilling basin block & $0.3 \times 0.3 \times 0.3$ & $0.25 \times 0.25 \times 0.25$ & $0.2 \times 0.2 \times 0.2$ & 0.1 & 94.63 \\
downstream river bed block & $0.5 \times 0.5 \times 0.5$ & $0.5 \times 0.5 \times 0.5$ & $0.5 \times 0.5 \times 0.5$ & 0.1 & 109.15 \\
\hline
\end{tabular}

In view of the unique grid generation technology in the Flow 3D software, as shown in Figure 2, the grid can be flexibly adjusted to embed into the walls of numerical model. In addition, as shown in Table 2, three different grid systems are arranged to fill the blocks to evaluate the effect of the grid size upon the numerical results [1, 19]. Each grid system, respectively, concludes $6.26 \mathrm{E}+06,3.61 \mathrm{E}+06$, and $2.09 \mathrm{E}+06$ elements. It can be noticed that the dimensionless $\mathrm{y}^{+}$in all grid systems ranges from 46.71 to 109.15 and confirms the requirement of the wall function method. The Reynolds number among the discharging flow in the stilling basin reaches $2.4 \sim 4.8 \mathrm{E}+08$ and the hydraulic diameter ranges between 17.9 and $29.9 \mathrm{~m}$ in all conditions.

2.6. Computation of the Free Water Surface. There are two main methods to trace the free surface among the numerical software, one is the Marker and Cell (MAC) method and the other is the volume of fluid (VOF) method. The MAC method mainly utilizes the uniformly distributed marking points to trace the movements inside the control volume. But the calculation accuracy of such method is strongly dependent on the density of marking points. Thus, such method is more suitable for two-dimensional model in view of the huge computational workload in the 3D numerical model [25].

The VOF method utilizes a filling process to explain the compositions inside each control volume. Assuming that both kinds of phases (water and air) would not interpenetrate into each other, a volume fraction (F) is adopted to represent how much percentage the computational cell is occupied by the phase. Compared to the MAC method, the VOF method is much more applicable for $3 \mathrm{D}$ complicated flow field in view of small computation memory [26]. $F=0$ means the computational cell is empty without any water; $\mathrm{F}=1$ means the computational cell is filled with water; $\mathrm{F}=0 \sim 1$ means the computational cell is partially filled with water, which is the case of free surface inside the computational cell. Among the Cartesian coordinate system $(\mathrm{x}, \mathrm{y}, \mathrm{z})$, the volume fraction $\mathrm{F}$ can be described as below equation.

$$
\frac{\partial F}{\partial t}+u \frac{\partial F}{\partial x}+v \frac{\partial F}{\partial y}+w \frac{\partial F}{\partial z}=0
$$

where $\mathrm{u}, \mathrm{v}$, and $\mathrm{w}$ are the fluid velocity components in the $\mathrm{x}, \mathrm{y}$, and $\mathrm{z}$ directions.

The generalized geometric reconstruction for unstructured grids is one of the most popular schemes to capture the free surface among the VOF applications. During the calculation process, the first step is to deduce the position of the linear interface between the air and the water on the basis of information about the volume fraction $\mathrm{F}$ and its derivatives. Then the second step is to determine the advecting amount of water through each face based on the normal and tangential velocity distribution on the cell. The last step is to determine the volume fraction in each cell with the balance of mass fluxes calculated in previous step [20,27].

2.7. Numerical Solution. The finite-volume method is used to solve the RANS equations with a single-fluid approach $[1,19]$. The semi-implicit method for pressure-linked equations (SIMPLE) algorithm is employed for velocity-pressure coupling. A first-order upwind discretization scheme is used for the momentum, turbulent kinetic energy, and dissipation equations. Moreover, the pressure staggered option (PRESTO) algorithm is used for the discretization of the pressure term. For each grid, averaged values (velocity and pressure) are computed at discrete times with a staggered grid technology. The staggered grid technology places all the parameters at the center of each grid except for the variables of velocities and fractional areas. Conversely, velocities and fractional areas are located at the center of grid faces (not grid centers), normal to the associated directions.

To accelerate the numerical simulation, some water is initially arranged inside the blocks to reduce reciprocating perturbations (hot start). The total simulation process is performed on a PC with four parallel $3.20 \mathrm{GHz}$ i5 processors. Stamou et al. [3] noted that at least $70 \mathrm{~s}$ was required to reach a steady state condition in the Flow 3D simulation process. Consequently, the total simulation time is set to be $200 \mathrm{~s}$ in the numerical simulation process.

2.8. Grid Sensitivity Analysis. A grid convergence study is performed to validate the influence of grid sizes upon the numerical results. Following the procedure of Roache [28] and Celik et al. [29], a Grid Convergence Index (GCI) is applied into the numerical simulation to determine the velocity results for three different grid sizes. Such method has proved to be a reliable technique for the discretization uncertainty analysis [20]. The fine GCI can be defined as following:

$$
G C I_{23}^{\text {fine }}=\frac{1.25\left|E_{23}\right|}{r_{23}{ }^{P}-1}
$$

where $E_{23}=\left(u_{2}-u_{3}\right) / u_{3}$ and represents the relative error between the medium and fine grids; $u_{2}$ and $u_{3}$ are the computed velocities from the medium and fine grid solutions; $P$ is the local order of accuracy and can be iterated to figure out through

$$
P=\frac{1}{\ln r_{23}} \ln \frac{\left(r_{23}^{P}-1\right) e_{12}}{\left(r_{12}^{P}-1\right) e_{23}}
$$


TABLE 3: Discretization error estimation in measured point $(\mathrm{x}, \mathrm{y}, \mathrm{z})=(10.5,31,1127)$ for RNG in Condition 3.

\begin{tabular}{lc}
\hline Parameters & Values \\
\hline $\mathrm{r}_{12}, \mathrm{r}_{23}$ & $1.20,1.25$ \\
$\mathrm{u}_{1}, \mathrm{u}_{2}, \mathrm{u}_{3}$ & $8.47,8.54,8.59$ \\
$\mathrm{P}$ & 2.68 \\
$\mathrm{GCI}$ & $0.89 \%$ \\
\hline
\end{tabular}

where e represents the differences between different grids; $e_{12}=u_{1}-u_{2}, e_{23}=u_{2}-u_{3} ; r$ represents the refinement factor between the different grids. $r_{12}=\Delta h_{1} / \Delta h_{2}, r_{23}=\Delta h_{2} / \Delta h_{3}$.

In the current paper, the numerical results about the stilling basin (Block 2) are the most concerned. As shown in Table 2, the block is particularly compacted with different grids in different systems and the grid sizes $\left(\Delta \mathrm{h}_{1}, \Delta \mathrm{h}_{2}\right.$, and $\Delta \mathrm{h}_{3}$ ) are $0.3 \mathrm{~m}, 0.25 \mathrm{~m}$, and $0.20 \mathrm{~m}$, respectively. The computed velocities are adopted along the lateral section $(\mathrm{Y}=31 \mathrm{~m}$, $\mathrm{Y}=64 \mathrm{~m}$, and $\mathrm{Y}=95 \mathrm{~m})$ among horizontal section $(\mathrm{Z}=1127 \mathrm{~m})$ to validate the numerical uncertainties, among which each lateral section is averagely divided into 9 points.

Taking the velocity results from the RNG model in Condition 3, for example, the discretization error estimations for different grid systems are, respectively, shown in Tables 3 and 4 . Table 3 shows the result of middle point $(x, y, z)=(10.5$, 31,1127 ) in the upstream section of $Y=31 \mathrm{~m}$ and Table 4 shows all the results in all the three sections. It can be noticed that the maximum GCI value among all the points ranges from $0.66 \%$ to $1.41 \%$ and stays within $2 \%$, which is very acceptable for numerical verification of computed results [20, 30]. Therefore, it can be decided that the grid-independent solution has been achieved and there is no need for further refinement for grid size. The subsequent numerical results are all based on Grid 3.

\section{Results and Discussion}

3.1. Validation of Numerical Model. As an alternative method to simulate the flow field, the numerical results should be validated before being applied into the practical engineering cases. Thus, the discharge flow rates and computed velocities along partial sections are specially adopted herein to facilitate a mutual comparison with the experimental results. The discharge flow rates in each scheme are all revealed in Table 5, among which $\varepsilon_{\text {re }}$ is the relative differences between the numerical and physical results. It can be noticed from Table 5 that the discharge flow rates among all turbulence models are much close to that of the physical results with maximum relative differences $\left(\varepsilon_{\mathrm{re}}\right)$ lower than $5 \%$, indicating the numerical results to be reliable. In addition, comparing the results in each condition, the discharge flow rates among the separated stilling basin scheme are much similar to the compound stilling basin scheme. It can be believed that there is almost no significant impact of the removed splitter wall upon the discharge capacity of overflow weir.

Furthermore, referred to the discharging flow of bottom layer $(0.5 \mathrm{~m}$ above the slab) in the physical model, elevations about the computed velocities along the lateral sections of
$\mathrm{Y}=10 \mathrm{~m}, 20 \mathrm{~m}, 30 \mathrm{~m}, 40 \mathrm{~m}, 50 \mathrm{~m}, 60 \mathrm{~m}, 70 \mathrm{~m}, 80 \mathrm{~m}$, and $90 \mathrm{~m}$ are performed to reveal the mean square error (MSE) and the mean absolute relative error (MARE). The MSE and MARE can be calculated with following equations.

$$
\begin{gathered}
M S E=\frac{1}{N} \sum_{n=1}^{N}\left(\bar{u}_{m}-\bar{u}_{c}\right)^{2} \\
M A R E=\frac{1}{N} \sum_{n=1}^{N}\left|\frac{\bar{u}_{m}-\bar{u}_{c}}{\bar{u}_{m}}\right| \times 100 \%
\end{gathered}
$$

where $\bar{u}_{m}$ and $\bar{u}_{c}$ are the measured and computed mean velocities in each point. $\mathrm{N}$ is the total number of selected points along each lateral section $(\mathrm{N}=9)$. In the present paper, the bottom section $(0.5 \mathrm{~m}$ above the structure surface) is adopted to reveal the velocity distribution and each lateral section is averagely divided into 9 points. As shown in Tables 6,7 , and 8 , the MSE and MARE values along each section $(\mathrm{Y}=10 \mathrm{~m}, 20 \mathrm{~m}, 30 \mathrm{~m}, 40 \mathrm{~m}, 50 \mathrm{~m}, 60 \mathrm{~m}, 70 \mathrm{~m}, 80 \mathrm{~m}$, and $90 \mathrm{~m})$ in the compound stilling basin scheme are all revealed, among which the numbers in parentheses represents the rank order of turbulence model with regards to compliance with the physical model.

Comprehensively observing Tables 6, 7, and 8 in detail, the computed velocities from all the turbulence models show great agreement with the measured values. However, there are some discrepancies at the upstream region of the stilling basin ( $\mathrm{Y}=20 \sim 50 \mathrm{~m})$, which may be attributable to the fluctuating hydraulic jump herein. But the maximum MSE and MARE values only reach $0.466 \mathrm{~m}^{2} \bullet \mathrm{s}^{2}$ and $5.732 \%$, respectively. At the downstream region ( $\mathrm{Y}=70 \sim 90 \mathrm{~m})$, both MSE and MARE values in all models gradually decrease almost to zero. All these results can prove the numerical simulation to be reliable.

Combined with Tables 5, 6, 7, and 8, it can be found that the RNG and SKE models rank the first and the second among the four models in predicting the numerical simulation. Thus, the subsequent descriptions are mainly based on these two models.

3.2. Experimental and Computed Velocity Distributions. The lateral velocity distributions among the horizontal section of upper layer $(\mathrm{Z}=1136 \mathrm{~m})$ are depicted in Figures 3, 4, and 5 to show the impact of splitter wall upon the downstream stilling basin, in which the horizontal section is successively divided with $\mathrm{Y}=20 \mathrm{~m}, 30 \mathrm{~m}, 45 \mathrm{~m}, 60 \mathrm{~m}, 80 \mathrm{~m}, 95 \mathrm{~m}$, and $105 \mathrm{~m}$. Furthermore, the computed velocities from the RNG and SKE models (Scheme 2) are adopted to make a mutual comparison with the experimental results to further validate the numerical accuracy. As shown in all figures, in can be noticed that the predicted velocities from both numerical models are much close to the experimental results. Even, the large-scale reverse flow can be accurately captured among the numerical models. Thus, it can be concluded that the numerical models are reliable. In addition, compared to the SKE model, the computed velocity distributions from the RNG model are much closer to that of the experimental results, indicating the RNG model to be more accurate. 
TABLE 4: GCI distribution among each section for RNG in Condition 3.

\begin{tabular}{lccccc}
\hline Section & Number of points & $\mathrm{P}_{\min }$ & $\mathrm{P}_{\max }$ & $\mathrm{P}_{\text {ave }}$ & ${\text { Maximum } G C I_{23}^{\text {fine }}(\%)}$ \\
\hline $\mathrm{Y}=31 \mathrm{~m}$ & 9 & 1.77 & 11.68 & 4.59 & $1.41 \%$ \\
$\mathrm{Y}=64 \mathrm{~m}$ & 9 & 3.8 & 8.05 & 5.41 & $0.66 \%$ \\
$\mathrm{Y}=95 \mathrm{~m}$ & 9 & 4.48 & 10.98 & 6.94 & $1.35 \%$ \\
\hline
\end{tabular}

TABLE 5: Discharge flow rates among each scheme.

\begin{tabular}{lcccccccccc}
\hline \multirow{2}{*}{ Scheme } & \multirow{2}{*}{ Condition } & Physical & \multicolumn{2}{c}{ SKE } & \multicolumn{2}{c}{ RNG } & \multicolumn{2}{c}{$\mathrm{RKE}$} & \multicolumn{2}{c}{$\mathrm{LES}$} \\
& & $\mathrm{Q}\left(\mathrm{m}^{3} \bullet \mathrm{s}\right)$ & $\mathrm{Q}\left(\mathrm{m}^{3} \bullet \mathrm{s}\right)$ & $\varepsilon_{\mathrm{re}}(\%)$ & $\mathrm{Q}\left(\mathrm{m}^{3} \cdot \mathrm{s}\right)$ & $\varepsilon_{\mathrm{re}}(\%)$ & $\mathrm{Q}\left(\mathrm{m}^{3} \cdot \mathrm{s}\right)$ & $\varepsilon_{\mathrm{re}}(\%)$ & $\mathrm{Q}\left(\mathrm{m}^{3} \cdot \mathrm{s}\right)$ & $\varepsilon_{\mathrm{re}}(\%)$ \\
\hline \multirow{3}{*}{ Separated stilling basin } & 1 & 222.5 & 218.4 & 1.84 & 219.2 & 1.48 & 215.4 & 3.19 & 214.5 & 3.60 \\
& 2 & 233.4 & 228.3 & 2.19 & 230.2 & 1.37 & 229.1 & 1.84 & 225.1 & 3.56 \\
& 3 & 452.6 & 443.5 & 2.01 & 449.1 & 0.77 & 440.5 & 2.67 & 435.9 & 3.69 \\
\hline \multirow{3}{*}{ Compound stilling basin } & 1 & 223.1 & 219.4 & 1.66 & 220.1 & 1.34 & 216.2 & 3.09 & 213.9 & 4.12 \\
& 2 & 233.9 & 229.3 & 1.97 & 231.6 & 0.98 & 228.5 & 2.31 & 226.8 & 3.04 \\
& 3 & 453.2 & 445.1 & 1.79 & 450.9 & 0.51 & 441.2 & 2.65 & 437.1 & 3.55 \\
\hline
\end{tabular}

TABLE 6: MSE and MARE values in Condition 1 among the compound stilling basin scheme.

\begin{tabular}{|c|c|c|c|c|c|c|c|c|}
\hline \multirow[b]{2}{*}{ Y } & \multicolumn{2}{|c|}{ SKE } & \multicolumn{2}{|c|}{ RNG } & \multicolumn{2}{|c|}{ RKE } & \multicolumn{2}{|c|}{ LES } \\
\hline & MSE & MARE & MSE & MARE & MSE & MARE & MSE & MARE \\
\hline$/ \mathrm{m}$ & $/ \mathrm{m}^{2} \cdot \mathrm{s}^{2}$ & $1 \%$ & $/ \mathrm{m}^{2} \cdot \mathrm{s}^{2}$ & $1 \%$ & $/ \mathrm{m}^{2} \cdot \mathrm{s}^{2}$ & $1 \%$ & $/ \mathrm{m}^{2} \cdot \mathrm{s}^{2}$ & $1 \%$ \\
\hline 10 & 0.025 & 0.648 & 0.015 & 0.569 & 0.035 & 0.796 & 0.041 & 0.855 \\
\hline 20 & 0.075 & 4.256 & 0.123 & 3.854 & 0.085 & 4.584 & 0.105 & 5.643 \\
\hline 30 & 0.142 & 4.379 & 0.135 & 4.153 & 0.156 & 4.585 & 0.154 & 5.532 \\
\hline 40 & 0.121 & 3.975 & 0.109 & 3.985 & 0.125 & 4.269 & 0.168 & 5.075 \\
\hline 50 & 0.107 & 3.529 & 0.082 & 3.258 & 0.135 & 3.963 & 0.125 & 4.956 \\
\hline 60 & 0.101 & 3.257 & 0.075 & 3.876 & 0.096 & 3.814 & 0.095 & 4.584 \\
\hline 70 & 0.096 & 3.145 & 0.061 & 2.908 & 0.076 & 3.679 & 0.075 & 4.345 \\
\hline 80 & 0.067 & 3.178 & 0.043 & 2.695 & 0.053 & 3.846 & 0.049 & 4.87 \\
\hline 90 & 0.046 & 3.085 & 0.023 & 2.589 & 0.049 & 3.614 & 0.045 & 4.691 \\
\hline Mean & $0.087^{(2)}$ & $3.272^{(2)}$ & $0.074^{(1)}$ & $3.099^{(1)}$ & $0.090^{(3)}$ & $3.683^{(3)}$ & $0.095^{(4)}$ & $4.506^{(4)}$ \\
\hline
\end{tabular}

TABLE 7: MSE and MARE values in Condition 2 among the compound stilling basin scheme.

\begin{tabular}{|c|c|c|c|c|c|c|c|c|}
\hline \multirow[b]{2}{*}{$\begin{array}{l}\mathrm{Y} \\
/ \mathrm{m}\end{array}$} & \multicolumn{2}{|c|}{ SKE } & \multicolumn{2}{|c|}{ RNG } & \multicolumn{2}{|c|}{ RKE } & \multicolumn{2}{|c|}{ LES } \\
\hline & $\begin{array}{c}\text { MSE } \\
/ \mathrm{m}^{2} \bullet \mathrm{s}^{2}\end{array}$ & $\begin{array}{c}\text { MARE } \\
/ \%\end{array}$ & $\begin{array}{l}\text { MSE } \\
/ \mathrm{m}^{2} \cdot \mathrm{s}^{2}\end{array}$ & $\begin{array}{c}\text { MARE } \\
/ \%\end{array}$ & $\begin{array}{c}\text { MSE } \\
/ \mathrm{m}^{2} \bullet \mathrm{s}^{2}\end{array}$ & $\begin{array}{c}\text { MARE } \\
/ \%\end{array}$ & $\begin{array}{c}\text { MSE } \\
/ \mathrm{m}^{2} \cdot \mathrm{s}^{2}\end{array}$ & $\begin{array}{c}\text { MARE } \\
\quad \%\end{array}$ \\
\hline 10 & 0.026 & 0.858 & 0.025 & 0.748 & 0.036 & 0.985 & 0.023 & 0.855 \\
\hline 20 & 0.235 & 4.656 & 0.198 & 4.364 & 0.354 & 5.876 & 0.376 & 5.543 \\
\hline 30 & 0.364 & 3.965 & 0.285 & 4.125 & 0.465 & 6.565 & 0.453 & 5.743 \\
\hline 40 & 0.276 & 3.645 & 0.252 & 3.583 & 0.358 & 5.643 & 0.446 & 4.758 \\
\hline 50 & 0.212 & 3.532 & 0.167 & 3.282 & 0.245 & 4.767 & 0.342 & 4.543 \\
\hline 60 & 0.169 & 2.976 & 0.155 & 2.657 & 0.155 & 3.543 & 0.229 & 4.643 \\
\hline 70 & 0.152 & 2.523 & 0.125 & 1.533 & 0.152 & 2.123 & 0.153 & 3.534 \\
\hline 80 & 0.125 & 1.459 & 0.09 & 1.035 & 0.124 & 2.543 & 0.19 & 3.53 \\
\hline 90 & 0.09 & 1.75 & 0.08 & 1.536 & 0.142 & 2.645 & 0.142 & 2.954 \\
\hline Mean & $0.183^{(2)}$ & $2.818^{(2)}$ & $0.153^{(1)}$ & $2.540^{(1)}$ & $0.226^{(3)}$ & $3.854^{(3)}$ & $0.262^{(4)}$ & $4.011^{(4)}$ \\
\hline
\end{tabular}

Observing velocity distributions between two different schemes in detail, it can be noticed the velocity distributions in the dam body region $(\mathrm{Y}=20 \mathrm{~m})$ are almost the same between two schemes in all conditions, further indicating the little influence of splitter wall upon the dam body. But there exhibits great differences between both schemes in the downstream stilling basin. Due to the limited diffusion room inside the left part of the separated stilling basin (Scheme 1), the high-velocity discharging flow from the bottom outlet can only longitudinally move without any lateral diffusion, resulting in relatively hysteretic velocity decay in the upstream region of stilling basin. Thus, as shown in Figures 3(e), 3(f), 5(e), and 5(f), the velocities of mainstream from the bottom outlet can still reach $2.0 \sim$ 
TABLE 8: MSE and MARE values in Condition 3 among the compound stilling basin scheme.

\begin{tabular}{|c|c|c|c|c|c|c|c|c|}
\hline \multirow[b]{2}{*}{$\begin{array}{l}\mathrm{Y} \\
/ \mathrm{m}\end{array}$} & \multicolumn{2}{|c|}{ SKE } & \multicolumn{2}{|c|}{ RNG } & \multicolumn{2}{|c|}{ RKE } & \multicolumn{2}{|c|}{ LES } \\
\hline & $\begin{array}{l}\text { MSE } \\
/ \mathrm{m}^{2} \cdot \mathrm{s}^{2}\end{array}$ & $\begin{array}{c}\text { MARE } \\
/ \%\end{array}$ & $\begin{array}{l}\text { MSE } \\
/ \mathrm{m}^{2} \cdot \mathrm{s}^{2}\end{array}$ & $\begin{array}{c}\text { MARE } \\
1 \%\end{array}$ & $\begin{array}{l}\text { MSE } \\
/ \mathrm{m}^{2} \cdot \mathrm{s}^{2}\end{array}$ & $\begin{array}{c}\text { MARE } \\
/ \%\end{array}$ & $\begin{array}{c}\text { MSE } \\
/ \mathrm{m}^{2} \bullet \mathrm{s}^{2}\end{array}$ & $\begin{array}{c}\text { MARE } \\
/ \%\end{array}$ \\
\hline 10 & 0.019 & 0.875 & 0.014 & 0.785 & 0.024 & 0.893 & 0.025 & 0.865 \\
\hline 20 & 0.17 & 1.453 & 0.112 & 0.965 & 0.154 & 2.564 & 0.123 & 2.455 \\
\hline 30 & 0.263 & 2.563 & 0.247 & 1.973 & 0.468 & 3.142 & 0.466 & 5.732 \\
\hline 40 & 0.214 & 2.032 & 0.228 & 1.545 & 0.324 & 3.521 & 0.435 & 4.72 \\
\hline 50 & 0.287 & 1.762 & 0.225 & 1.642 & 0.285 & 2.543 & 0.353 & 4.433 \\
\hline 60 & 0.159 & 1.232 & 0.145 & 0.942 & 0.185 & 2.212 & 0.153 & 2.436 \\
\hline 70 & 0.107 & 1.962 & 0.046 & 0.825 & 0.154 & 2.233 & 0.105 & 2.545 \\
\hline 80 & 0.055 & 0.823 & 0.025 & 0.754 & 0.053 & 1.121 & 0.181 & 2.258 \\
\hline 90 & 0.021 & 0.756 & 0.021 & 0.685 & 0.022 & 1.832 & 0.125 & 2.987 \\
\hline Mean & $0.144^{(2)}$ & $1.495^{(2)}$ & $0.118^{(1)}$ & $1.124^{(1)}$ & $0.185^{(3)}$ & $2.229^{(3)}$ & $0.218^{(4)}$ & $3.159^{(4)}$ \\
\hline
\end{tabular}

$4.8 \mathrm{~m} / \mathrm{s}$ in the downstream region of the separated stilling basin $(Y=80-90 m)$. Such hysteretic energy dissipation would directly cause high-velocity outgoing flow. The maximum velocity among the outgoing flow can, respectively, reach $6.45 \mathrm{~m} / \mathrm{s}$ and $6.59 \mathrm{~m} / \mathrm{s}$ in Condition 1 and Condition 3. But in view of the suddenly expanding section outside the separated stilling basin (Scheme 1), both the left outgoing flow in Condition 1 and right outgoing flow in Condition 2 would significantly diffuse towards the other side and then form large-scale reverse flow outside the stilling basin. Similarly, due to the energy dissipation differences between both separated stilling basins, the left outgoing flow in Condition 3 would still maintain highly energetic while the right outgoing flow is relatively low energetic. Thus, there would form great velocity gradients and large-scale lateral diffusion among the outgoing flow in Condition 3. As shown in Table 9, in view of insufficient energy dissipation in the separated stilling basin, the maximum velocities of outgoing flows in three conditions, respectively, reach $6.45 \mathrm{~m} / \mathrm{s}, 2.31 \mathrm{~m} / \mathrm{s}$, and $6.59 \mathrm{~m} / \mathrm{s}$. Moreover, in view of the suddenly expanding section outside the separated stilling basin, the velocity gradients between the left and right outgoing flow successively reach as high as $7.61 \mathrm{~m} / \mathrm{s}, 2.28 \mathrm{~m} / \mathrm{s}$, and $4.78 \mathrm{~m} / \mathrm{s}$ in all conditions. Such situation of great velocity gradients is much easily to result in oblique erosion upon downstream dikes on both sides.

But such situation of highly uneven velocity outgoing flow can be significantly improved in the compound stilling basin (Scheme 2). As shown in Figures 3(b), 3(c), 3(d), 4(b), 4(c), and $4(\mathrm{~d})$, the inflow in Condition 1 and Condition 2 would diffuse towards the other side to form large-scale reverse flow in the upstream region of the compound stilling basin, greatly decreasing down the velocity of mainstream to be $1.5 \mathrm{~m} / \mathrm{s} \sim 2.0 \mathrm{~m} / \mathrm{s}$ in the downstream region. This is definitely attributable to the improved impingement and shear friction by the removed splitter wall. Similarly, in view of structure differences between surface outlet and bottom outlet, there exists velocity gradients among the pressurized jet from the bottom outlet and the free inflow from the surface outlet in Condition 3, thus promoting shear friction in the upstream region of the compound stilling basin. The velocity decay in the compound stilling basin is significantly enhanced in all conditions.

In general, compared to the separated stilling basin, high energy dissipation region in the compound stilling basin is significantly moved upstream in view of the removed splitter wall. As shown in Table 9, the maximum velocities among the outgoing flow in the compound stilling basin only reach $1.20 \mathrm{~m} / \mathrm{s}, 2.01 \mathrm{~m} / \mathrm{s}$, and $3.17 \mathrm{~m} / \mathrm{s}$ in three conditions, and the corresponding velocity gradients decrease as low as $0.47 \mathrm{~m} / \mathrm{s}$, $0.74 \mathrm{~m} / \mathrm{s}$, and $1.08 \mathrm{~m} / \mathrm{s}$, more than $65 \%$ lower than that of the separated stilling basin scheme.

3.3. Flow Pattern Comparisons. The flow pattern in the stilling basin presents great differences between both schemes. In view of the splitter wall, both adjacent stilling basins are quite independent in the separated stilling basin scheme. The pressurized jet from the bottom outlet in Condition 1 would not dive down but almost horizontally move, thus extending so far away. A repelled downstream hydraulic jump with fluctuating water can be clearly observed in the bottom outlet stilling basin, directly resulting in velocity decay to be hysteretic. In addition, in view of the suddenly expanding flow section outside the bottom outlet stilling basin, the highvelocity outgoing flow would greatly diffuse towards the right side and form large-scale reverse flow. Similarly, there can also observe lateral diffusion and local reverse flow outside the surface outlet stilling basin in Condition 2. There are only some slight improvements for the outgoing flow in Condition 3 but obliquely moving outgoing flow can still exist in view of the great velocity gradients (shown in Table 9).

But due to the removed splitter wall, both kinds of outlets can share the downstream compound stilling basin. Thus, the pressurized jet from the bottom outlet in Condition 1 would greatly offset to form a typical 3D hydraulic jump with largescale reverse flow in the right side of the compound stilling basin, significantly enhancing mutual impingement and shear friction among the discharging flow. Correspondingly, the discharging flow becomes much stable in the downstream region with much uniform lateral velocity distributions (as shown in Figure 3(f)). Therefore, there would not be any 


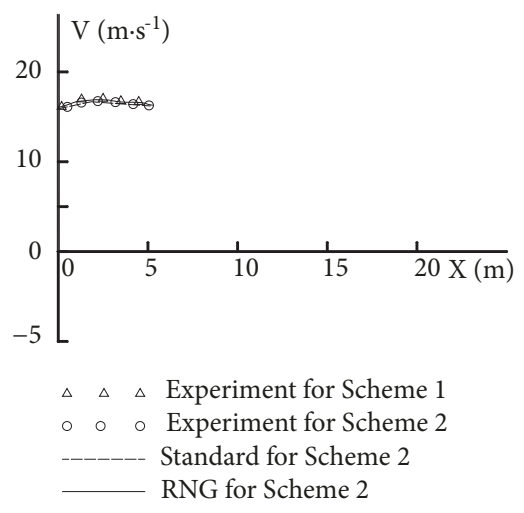

(a) $\mathrm{Y}=20 \mathrm{~m}$

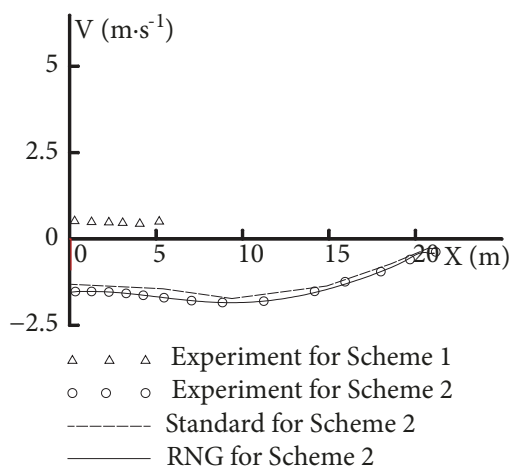

(d) $\mathrm{Y}=60 \mathrm{~m}$

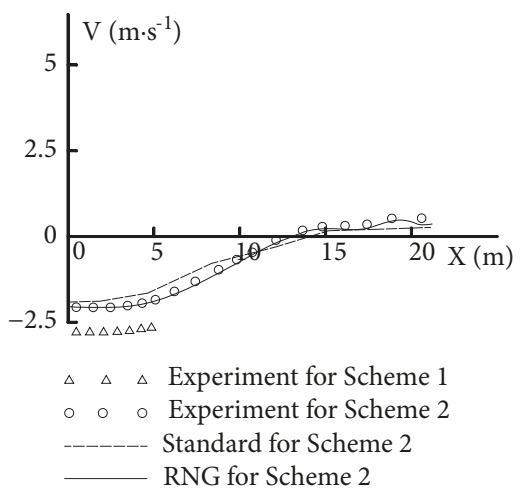

(b) $\mathrm{Y}=30 \mathrm{~m}$

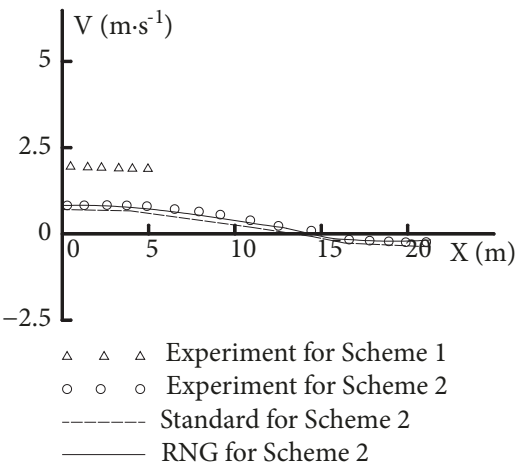

(e) $\mathrm{Y}=80 \mathrm{~m}$

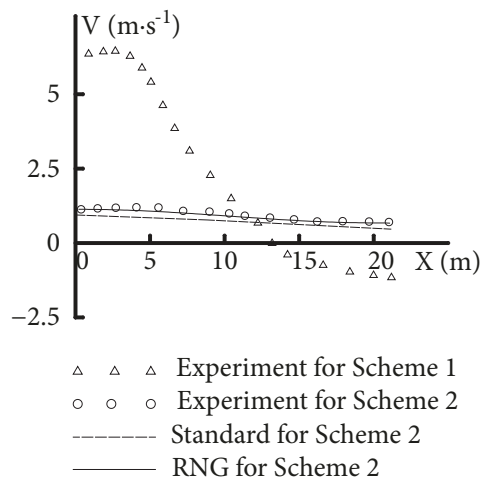

(g) $\mathrm{Y}=105 \mathrm{~m}$

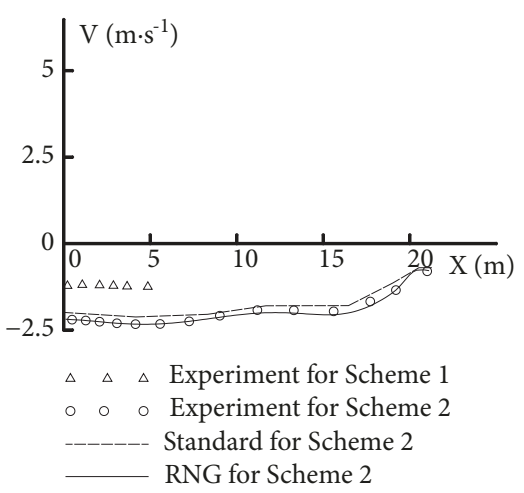

(c) $\mathrm{Y}=45 \mathrm{~m}$

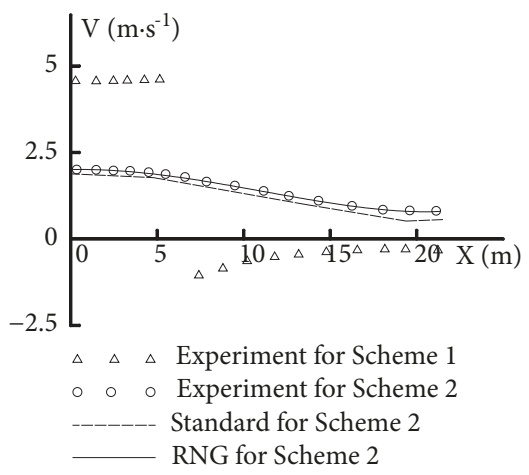

(f) $\mathrm{Y}=95 \mathrm{~m}$

FIgURE 3: Velocity distribution in Condition 1.

oblique movements among the outgoing flow in Condition 1. In view of the enlarged flow section, the free inflow from the surface outlet would also offset towards the left side and form large-scale reverse flow in Condition 2. Energy exchange is relatively sufficient and outgoing flow become much stable without any oblique movements. But, in view of the velocity gradients induced by the structure differences, the pressurized jet from the bottom outlet in Condition 3 would greatly diffuse towards right side to impinge upon the relatively low velocity inflow from the surface outlet. Such unique feature directly induces lateral diffusion with reverse flow in the upstream region of the compound stilling basin. Energy dissipation is greatly intensified and moved forward. As shown in Figure 5(f), compared to the separated stilling basin, velocities of discharging flow in the downstream region greatly decrease and become much uniform. Velocity gradients among the outgoing flow almost decrease to zero and the phenomenon of obliquely moving outgoing flow is eliminated.

3.4. Computed Velocity Vector and Involved Hydraulic Jump Length. To trace the movements of discharging flow inside the stilling basin, the longitudinal and horizontal sections are particularly adopted to reveal the velocity vectors. In view of the differences between each condition, the longitudinal sections would adopt Sections 1-1, 2-2 and 2-2 in all conditions and the horizontal section adopts the discharging flow of middle layer $(\mathrm{Z}=1132 \mathrm{~m})$. In addition, the $\mathrm{RNG}$ model are 


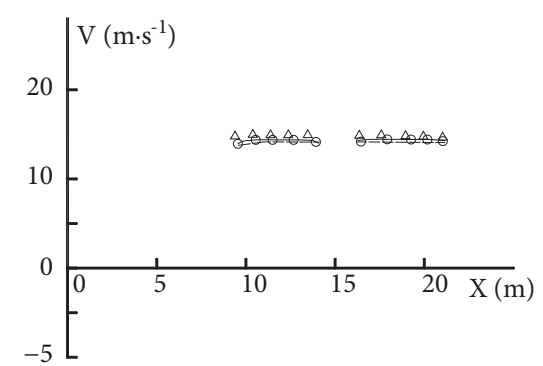

(a) $\mathrm{Y}=20 \mathrm{~m}$

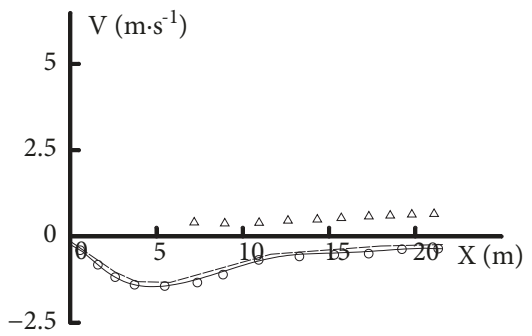

(d) $Y=60 \mathrm{~m}$

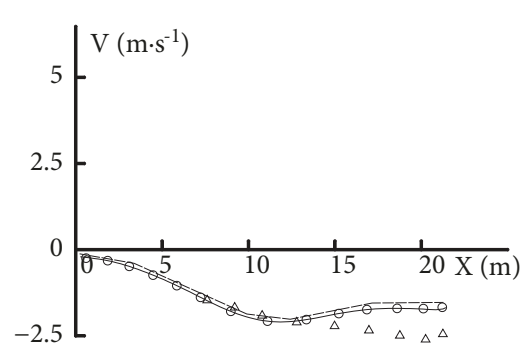

(b) $\mathrm{Y}=30 \mathrm{~m}$

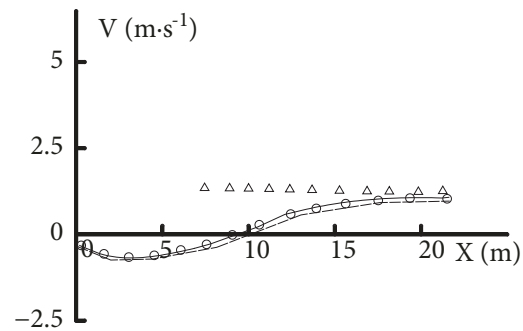

(e) $\mathrm{Y}=80 \mathrm{~m}$

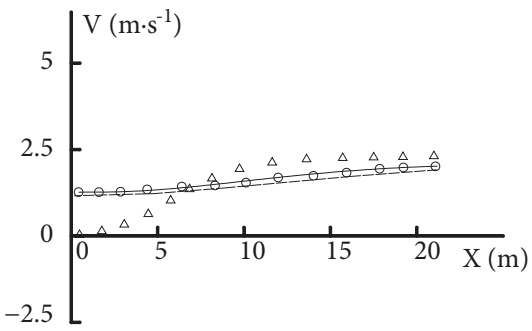

(g) $Y=105 m$

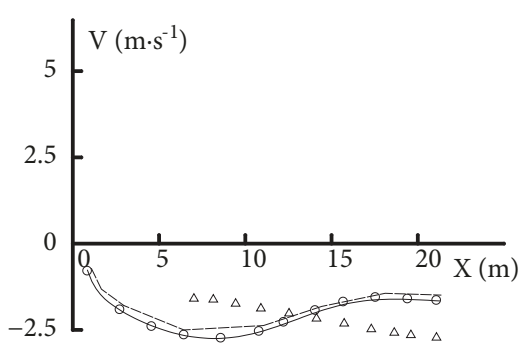

(c) $\mathrm{Y}=45 \mathrm{~m}$

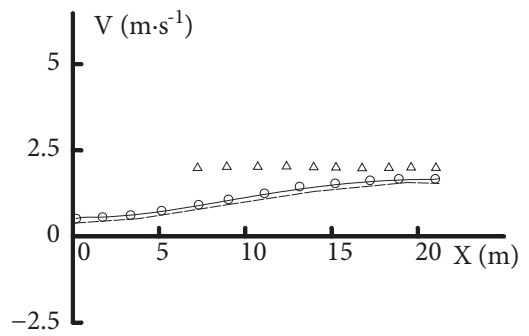

(f) $Y=95 \mathrm{~m}$

FIgure 4: Velocity distribution in Condition 2.

applied among the separated and compound stilling basin to figure out differences between both schemes and the computed velocity vectors from the SKE model are utilized to further verify the numerical accuracy.

As shown in Figure 6(a), in view of the limited diffusion room, the pressurized jet from the bottom outlet in Condition 1 does not dive down to form an expected submerged hydraulic jump, but almost moves parallel to the slab of stilling basin. The transverse vortex only focuses on the surface layer in the upstream region of the bottom outlet stilling basin. Longitudinal movements of discharging flow inside the stilling basin can be clearly revealed in Figure 7(a). But, outside the stilling basin, the longitudinally moving outgoing flow greatly diffuses towards the right side to form large-scale reverse flow. There are only some slight improvement about involved hydraulic jump length and diving down mainstream in the surface outlet stilling basin in Condition 2. As shown in Figure 7(b), the hydraulic jump length slightly increases to reach the middle part of the stilling basin. But, in view of the abruptly expanding cross section outside the stilling basin, outgoing flow also diffuses to form local reverse flow on the left side of downstream river bed (as shown in Figure 7(b)). The similar situation of obliquely moving outgoing flow can also be observed in Figure 7 (c) for Condition 3. In view of energy dissipation differences between both stilling basins, outgoing flow from the bottom outlet stilling basin still maintains high velocity while that of the surface outlet stilling basin remains low velocity, thus forming great velocity gradients among outgoing flows and resulting in lateral diffusion (shown in Figure 7(c)).

However, the discharging inflow in the compound stilling basin presents great differences. In view of the removed splitter wall, both kinds of outlets can share the stilling basin, thus the lateral flow section in the upstream region is greatly enlarged. As shown in Figures 7(d), 7(e), 7(g), and 7(h), it can be noticed from both numerical results that inflow from both outlets in Condition 1 and Condition 2 can greatly diffuse to form a typical 3D hydraulic jump with large-scale reverse flow in the upstream region of the compound stilling basin. Moreover, as shown in Figures 6(d), 6(e), 6(g), and $6(\mathrm{~h})$, the mainstream of discharging inflow slightly dives down to form deep transverse vortex with involved region moved forward and being much concentrated. With such sufficient momentum exchange and adjustment, discharging flow in the downstream region becomes much uniform with much slight velocity gradients; thus the situation of obliquely moving outgoing flow is eliminated. The similar situation of uniform outgoing flow in Condition 3 can also be noticed in Figures 7(f) and 7(i). In view of the removed splitter wall in the compound stilling basin, the high-velocity inflow from 


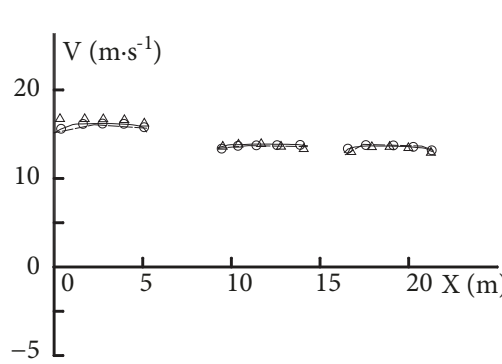

(a) $\mathrm{Y}=20 \mathrm{~m}$

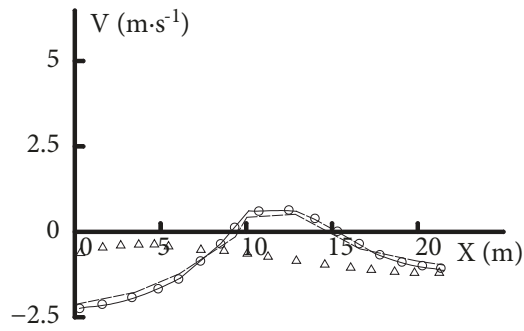

(d) $\mathrm{Y}=60 \mathrm{~m}$

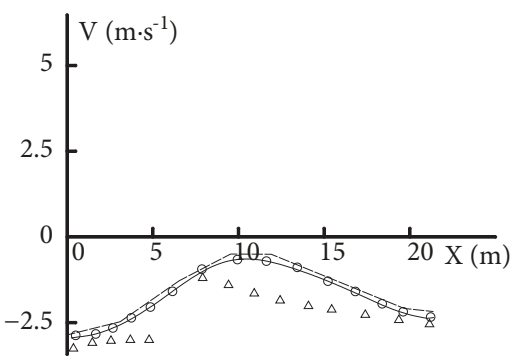

(b) $\mathrm{Y}=30 \mathrm{~m}$

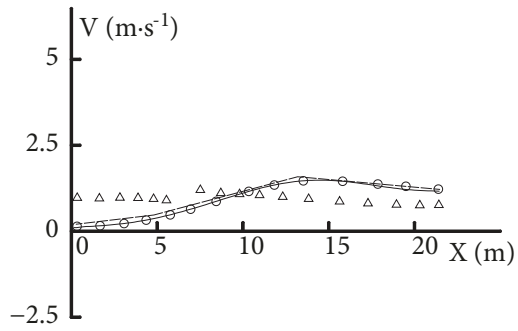

(e) $\mathrm{Y}=80 \mathrm{~m}$

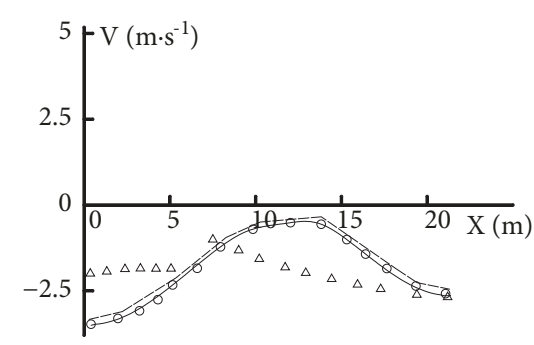

(c) $Y=45 \mathrm{~m}$

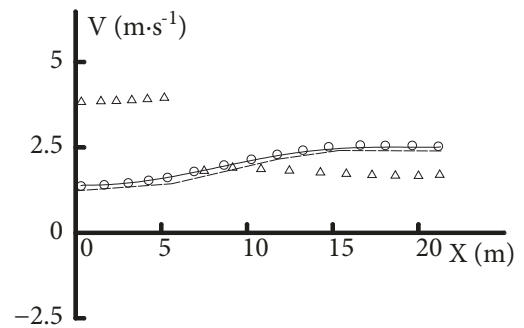

(f) $\mathrm{Y}=95 \mathrm{~m}$

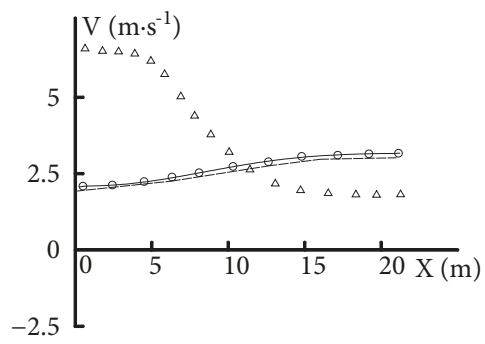

(g) $Y=105 \mathrm{~m}$

Figure 5: Velocity distribution in Condition 3.

TABLE 9: Details of maximum velocity among outgoing flow $(\mathrm{Y}=105 \mathrm{~m})$ in both schemes.

\begin{tabular}{lcccccc}
\hline \multirow{2}{*}{ Condition } & \multicolumn{3}{c}{ Separated stilling basin } & \multicolumn{3}{c}{ Compound stilling basin } \\
& Left & Right & Gradients & Left & Right & Gradients \\
\hline 1 & 6.45 & -1.16 & 7.61 & 1.20 & 0.73 & 0.47 \\
2 & 0.03 & 2.31 & 2.28 & 1.27 & 2.01 & 0.74 \\
3 & 6.59 & 1.81 & 4.78 & 2.09 & 3.17 & 1.08 \\
\hline
\end{tabular}

the bottom outlet would greatly diffuse towards the right side to impinge upon the relatively low-velocity inflow from the surface outlet, thus forming vertical vortex in the upstream region of the compound stilling basin (shown in Figures $7(\mathrm{f})$ and $7(\mathrm{i})$ ). In addition, it can be noticed from Figures 6(f) and 6(i) that surface rollers move upstream and become much more concentrated relative to that of the separated stilling basin. Such unique properties of transverse vortex and vertical vortex can not only maintain the vertical flow separation of the $2 \mathrm{D}$ traditional hydraulic jump but also induce great complicated diffusion among the discharging flow. These complicated movements would greatly adjust the discharging flow.

Comprehensively observing Figures 6 and 7 in detail, it can be found that the removed splitter wall exerts great impact upon the downstream stilling basin. The discharging inflow in the compound stilling basin can greatly diffuse to form a typical 3D hydraulic jump with diving down transverse vortex. Moreover, compared to the $2 \mathrm{D}$ hydraulic jump in the separated stilling basin, the 3D hydraulic jump in the compound stilling basin slightly moves upstream to involve much wider region. The details about hydraulic jump length and mainstream depth above the stilling basin slab are summarized in Table 10. In general, the hydraulic jump length in the compound stilling basin is about 1.2 1.6 times that of the separated stilling basin, but the mainstream depth only reaches about 0.65 in both Condition 1 and 2 and much the same in Condition 3. Such details can further indicate that energy dissipation and momentum exchange in the compound stilling basin are much more sufficient than that of the separated stilling basin. Kordi and Abustan [2] and Omid [6] also observed such properties of slightly longer hydraulic jump length in the expanding stilling basin and proved the increasement about energy dissipation among the discharging flow.

3.5. Computed Turbulent Kinetic Energy. The turbulent kinetic energy $(\kappa)$ is an important characteristic index to reflect the energy dissipation extent among the discharging flow. Usually, the values would increase up (or decrease 
TABLE 10: Hydraulic jump length and mainstream depth.

\begin{tabular}{lcccc}
\hline Condition & $\begin{array}{c}\text { Separated stilling basin } \\
\text { Experiment }\end{array}$ & Experiment & Compound stilling basin \\
RNG model & Standard model \\
\hline 11 & $25-60(5.25)$ & $25-73(3.56)$ & $25-75(3.48)$ & $25-78(3.41)$ \\
22 & $25-65(3.36)$ & $23-72(2.15)$ & $20-70(2.23)$ & $23-68(2.09)$ \\
33 & $20-68(3.25)$ & $22-72(3.20)$ & $20-70(3.25)$ & $20-70(3.35)$ \\
\hline
\end{tabular}

Notification: the values in parentheses are the mainstream depth above the stilling basin slab.

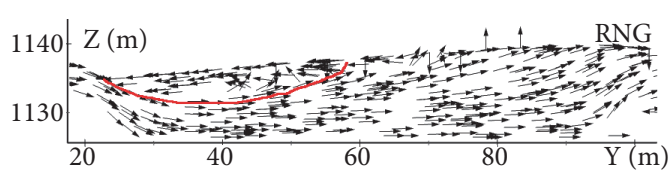

(a) Separated stilling basin in Condition 1 (Section 1-1)

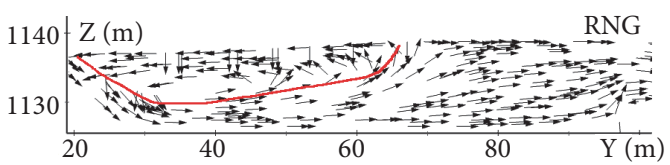

(c) Separated stilling basin in Condition 3 (Section 2-2)

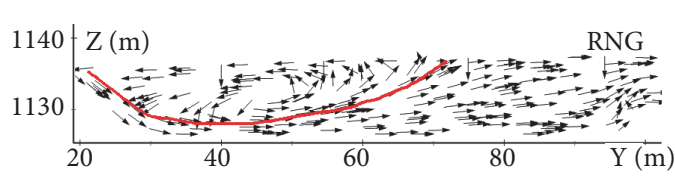

(e) Compound stilling basin in Condition 2 (Section 2-2)

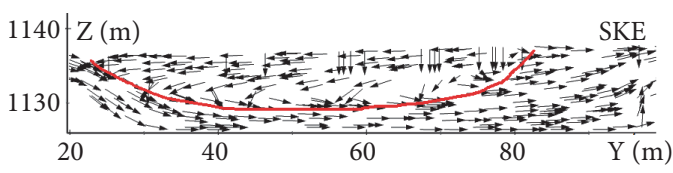

(g) Compound stilling basin in Condition 1 (Section 1-1)

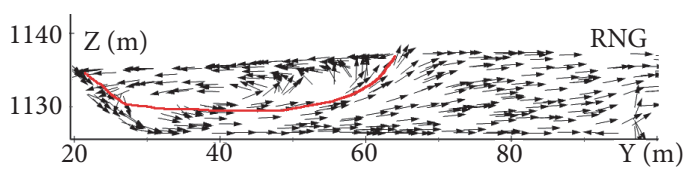

(b) Separated stilling basin in Condition 2(Section 2-2)

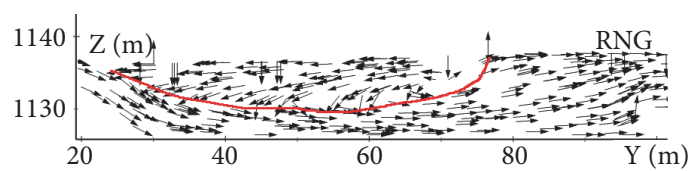

(d) Compound stilling basin in Condition 1 (Section 1-1)

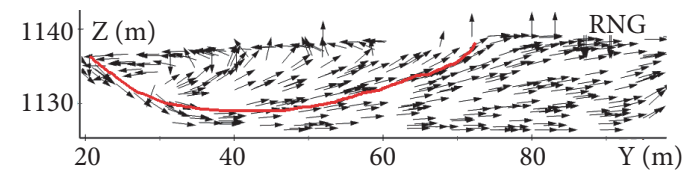

(f) Compound stilling basin in Condition 3 (Section 2-2)

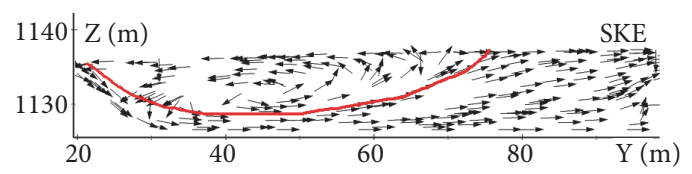

(h) Compound stilling basin in Condition 2 (Section 2-2)

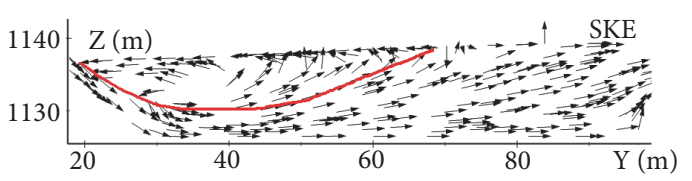

(i) Compound stilling basin in Condition 3 (Section 2-2)

FIGURE 6: Longitudinal velocity vectors in both schemes. Notification: the red line in the above pictures represent the trace of mainstream.

down) where the energy dissipation is fierce (or insufficient) for turbulent flow. In view of the unique property about 3D hydraulic jump in the compound stilling basin, both the longitudinal and horizontal sections are adopted to describe the turbulent kinetic energy variation. The longitudinal sections are successively along Sections 1-1, 2-2, and 2-2 in three conditions and the horizontal section adopts the middle layer of discharging flow $(\mathrm{Z}=1132 \mathrm{~m})$.

To make a convenience for mutual comparison among both schemes, the colour bar among all sections is set as 0 $10 \mathrm{~m}^{2} / \mathrm{s}^{2}$. As shown in Figures $8(\mathrm{a})$ and $9(\mathrm{a})$, the mainstream of discharging flow from the bottom outlet in Condition 1 does not dive down but almost runs parallel to the stilling basin slab, thus resulting in hysteretic energy dissipation and much wide sweep region $(\mathrm{Y}=30 \sim 80 \mathrm{~m})$ in the separated stilling basin. The turbulent kinetic energy value among the outgoing flow from the bottom outlet stilling basin is still as high as $7.8 \mathrm{~m}^{2} / \mathrm{s}^{2}$. But the flow inside the adjacent surface outlet stilling basin is almost motionless. Therefore, there exist great gradients among the outgoing flow and the maximum $\kappa$ value ranges from $7.8 \mathrm{~m}^{2} / \mathrm{s}^{2}$ to $2.4 \mathrm{~m}^{2} / \mathrm{s}^{2}$ from the left to the right, which is quite corresponding to the situation of insufficient energy dissipation and obliquely moving outgoing flow. The similar situation of uneven outgoing flow can also be observed in Figure 9(b) for Condition 2. But, as shown in Figure 9(c), even though there comes outgoing flow from both adjacent stilling basins in Condition 3, there still exist great turbulent kinetic energy gradients among the outgoing flow in view of energy dissipation differences between adjacent stilling basins. The maximum $\kappa$ values still 


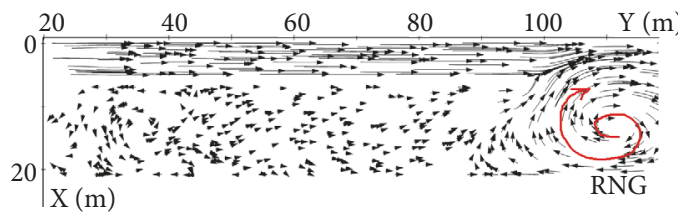

(a) Separated stilling basin in Condition 1

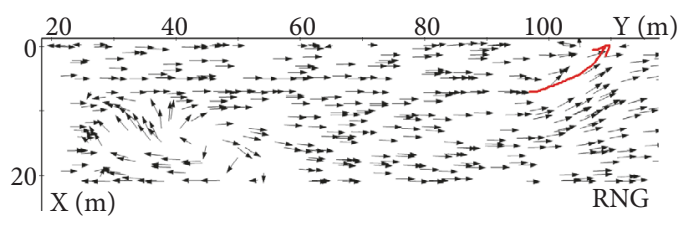

(c) Separated stilling basin in Condition 3

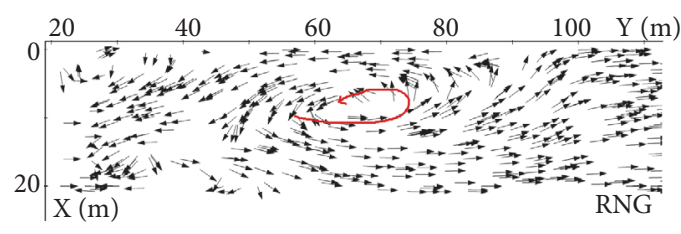

(e) Compound stilling basin in Condition 2

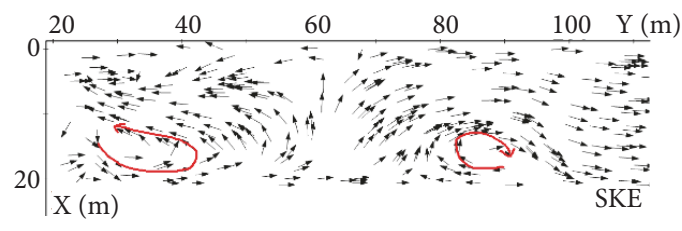

(g) Compound stilling basin in Condition 1

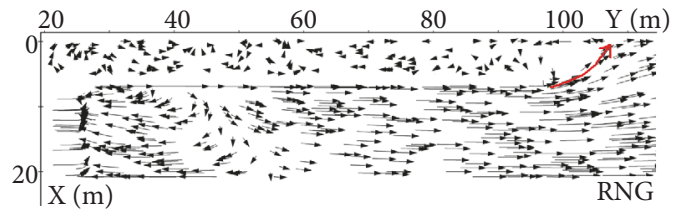

(b) Separated stilling basin in Condition 2

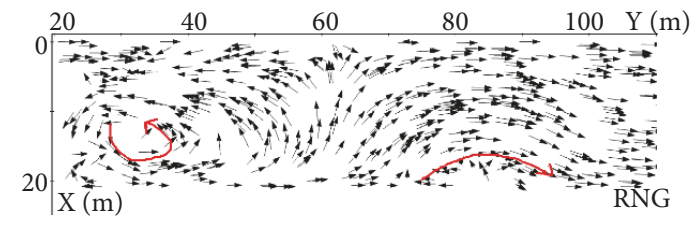

(d) Compound stilling basin in Condition 1

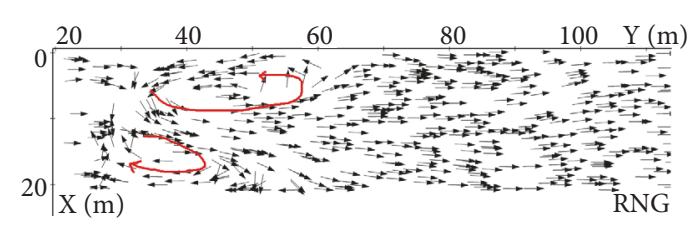

(f) Compound stilling basin in Condition 3

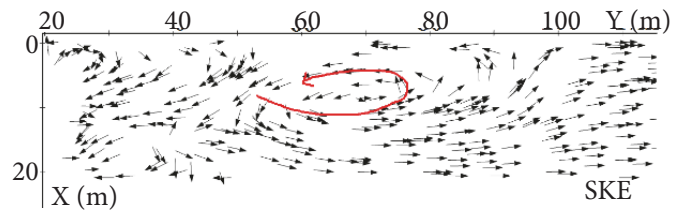

(h) Compound stilling basin in Condition 2

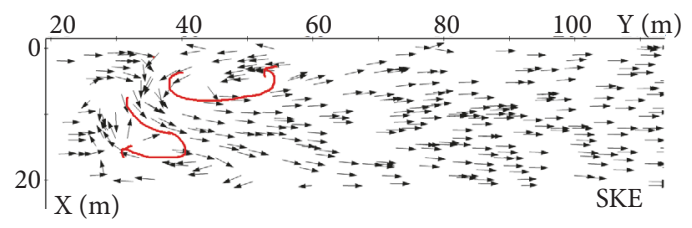

(i) Compound stilling basin in Condition 3

Figure 7: Horizontal velocity vectors in both schemes. Notification: the red line in above pictures represent the direction of vertical vortex.

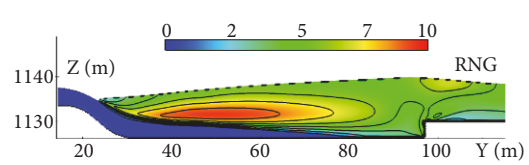

(a) Condition 1 for separated stilling basin scheme

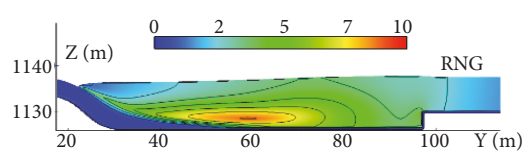

(d) Condition 1 for compound stilling basin scheme

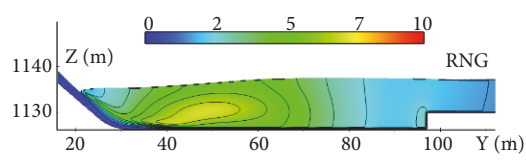

(b) Condition 2 for separated stilling basin scheme

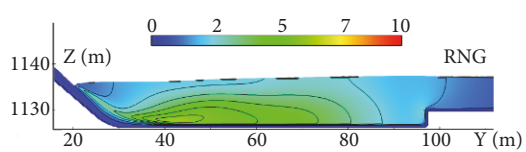

(e) Condition 2 for compound stilling basin scheme

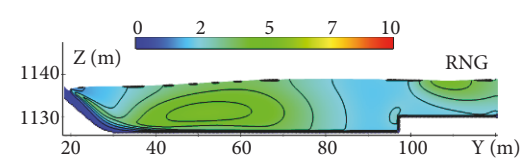

(c) Condition 3 for separated stilling basin scheme

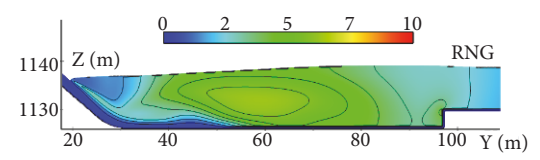

(f) Condition 3 for compound stilling basin scheme

FIGURE 8: Longitudinal turbulent kinetic energy distribution (Unit: $\mathrm{m}^{2} / \mathrm{s}^{2}$ ). 


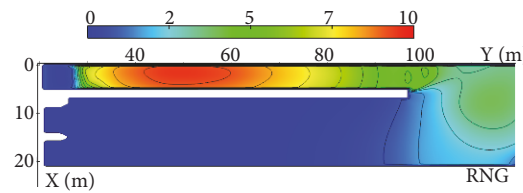

(a) Condition 1 for separated stilling basin scheme

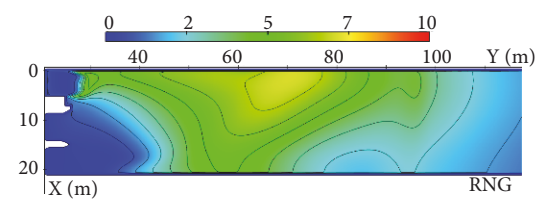

(d) Condition 1 for compound stilling basin scheme

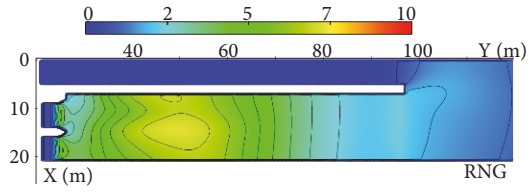

(b) Condition 2 for separated stilling basin scheme

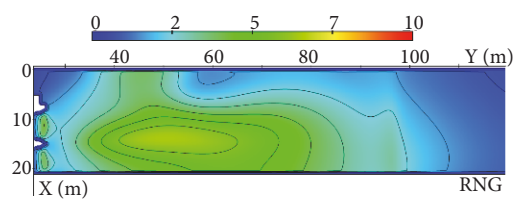

(e) Condition 2 for compound stilling basin scheme

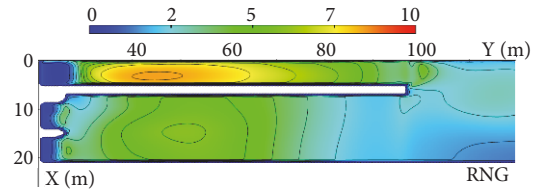

(c) Condition 3 for separated stilling basin scheme

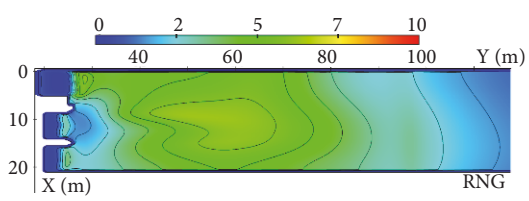

(f) Condition 3 for compound stilling basin scheme

FIGURE 9: Horizontal turbulent kinetic energy distribution (Unit: $\mathrm{m}^{2} / \mathrm{s}^{2}$ ).

range from $5.8 \mathrm{~m}^{2} / \mathrm{s}^{2}$ to $2.1 \mathrm{~m}^{2} / \mathrm{s}^{2}$ from the left to the right outgoing flow.

But in view of the removed splitter wall in the compound stilling basin, discharging inflow in all conditions present great differences. Compared to the separated stilling basin, the maximum $\kappa$ values in the compound stilling basin may slightly decrease to $9.5 \mathrm{~m}^{2} / \mathrm{s}^{2}$ and $6.5 \mathrm{~m}^{2} / \mathrm{s}^{2}$ in Condition 1 and Condition 2, but the sweep regions are significantly broadened to laterally cover the whole stilling basin (as shown in Figures 9(d) and 9(e)). In addition, as shown in Figures $8(\mathrm{~d})$ and $8(\mathrm{e})$, the mainstream of discharging inflow vertically dives down and the high $\kappa$ values become much more concentrated into the upstream region of the compound stilling basin. Thus, the $\kappa$ values among the outgoing flow decrease and become much uniform. As shown in Figures $8(\mathrm{f})$ and $9(\mathrm{f})$, the similar situation of uniform outgoing flow can also be observed in Condition 3, which can be explained by the enhanced mutual impingement in the upstream region among the adjacent inflow from both outlets. Thus, the turbulent kinetic energy gradients great decrease to almost zero.

Summarizing the details between Figures 8 and 9, it can be noticed that the longitudinal and horizontal distributions about turbulent kinetic energy present great differences among both schemes. In general, compared to the separated stilling basin scheme, high turbulent dissipation regions in the compound stilling basin scheme are moved upstream and become much more concentrated. In addition, as shown in Table 11, the maximum turbulent kinetic energy values among the outgoing flow, respectively, reach $2.0 \mathrm{~m}^{2} / \mathrm{s}^{2}, 2.1$ $\mathrm{m}^{2} / \mathrm{s}^{2}$, and $1.8 \mathrm{~m}^{2} / \mathrm{s}^{2}$ in the compound stilling basin scheme in three conditions, which is successively $76.9 \%, 32.0 \%$, and $70.7 \%$ lower than that of the separated stilling basin scheme. Gradients between the left and right outgoing flow almost decrease to zero in the compound stilling basin scheme, far lower than that of the separated stilling basin scheme.

3.6. Experimental and Computed Free Surface Profiles. Figure 10 shows the measured and computed free surface profiles in all conditions. The three conditions, respectively,
TABLE 11: Maximum turbulent kinetic energy among the outgoing flow in $\mathrm{Y}=105$ section (unit: $\mathrm{m}^{2} / \mathrm{s}^{2}$ ).

\begin{tabular}{lcccccc}
\hline \multirow{2}{*}{ Condition } & \multicolumn{3}{c}{ Separated stilling basin } & \multicolumn{3}{c}{ Compound stilling basin } \\
& Left & Right & Gradients & Left & Right & Gradients \\
\hline 11 & 7.8 & 2.4 & 5.4 & 2.0 & 1.8 & 0.2 \\
22 & 2.5 & 2.0 & 0.5 & 2.1 & 1.7 & 0.4 \\
33 & 5.8 & 2.1 & 3.7 & 1.8 & 1.7 & 0.1 \\
\hline
\end{tabular}

adopt Sections 1-1, 2-2, and 2-2 to describe the influence of removed splitter wall. It can be noticed from all figures that the computed free surface profiles from the RNG model show acceptable agreement with the experimental results. In addition, the free surface profiles in the dam body region $(\mathrm{Y}=0 \sim 20 \mathrm{~m})$ from both schemes almost overlap with each other, indicating little influence of removed splitter wall upon the dam body. But there presents slight differences in the downstream stilling basin regions between both schemes.

The discharging inflow in Condition 1 gradually increase in the downstream region of the separated stilling basin and the highest water level even reaches $1139.44 \mathrm{~m}$, slightly higher than the splitter wall top $(Z=1138.5 \mathrm{~m})$. The similar situation of increasing water level in the separated stilling basin can also be observed in Condition 2 and Condition 3 with maximum water level, respectively, to be $1137.57 \mathrm{~m}$ and $1138.23 \mathrm{~m}$. But in view of the removed splitter wall, lateral cross section is significantly enlarged in the compound stilling basin. Thus, discharging inflow can greatly offset to decrease down the water level. As shown in Figures 10(a), 10(b), and 10(c), the maximum water level in the compound stilling basin only reaches $1137.73 \mathrm{~m}, 1137.50 \mathrm{~m}$, and $1138.3 \mathrm{~m}$ in all conditions. In general, the water depths in the downstream region of the compound stilling basin are slightly lower than that of the separated stilling basin in Condition 1 but much close to that of the separated stilling basin in Conditions 2 and 3.

3.7. Energy Dissipation Rate inside the Stilling Basin. In the practical engineering applications, the index of energy dissipation rate, representing total water head differences between 
TABLE 12: Energy dissipation rates in each scheme.

\begin{tabular}{lcccccccc}
\hline Scheme & Condition & $\begin{array}{c}\text { Inflow section } \\
\text { Potential } \\
\text { energy/m }\end{array}$ & $\begin{array}{c}\text { Average } \\
\text { velocity/m॰s }\end{array}$ & $\begin{array}{c}\text { Total } \\
\text { head/m }\end{array}$ & $\begin{array}{c}\text { Outgoing flow section } \\
\text { Potential } \\
\text { energy/m }\end{array}$ & $\begin{array}{c}\text { Average } \\
\text { velocity/m॰s }\end{array}$ & $\begin{array}{c}\text { Total } \\
\text { head/m }\end{array}$ & $\begin{array}{c}\text { Energy dissipation } \\
\text { rate }\end{array}$ \\
\hline Separated & 1 & 17 & 0.73 & 17.03 & 8.92 & 4.85 & 10.12 & 0.41 \\
stilling basin & 2 & 17 & 0.87 & 17.04 & 7.2 & 2.07 & 7.42 & 0.56 \\
& 3 & 17 & 1.22 & 17.08 & 8.62 & 3.23 & 9.15 & 0.46 \\
Compound & 1 & 17 & 0.75 & 17.03 & 7.59 & 1.74 & 7.74 & 0.55 \\
stilling basin & 2 & 17 & 0.9 & 17.04 & 7.15 & 1.45 & 7.26 & 0.57 \\
& 3 & 17 & 1.23 & 17.08 & 8.75 & 2.49 & 9.07 & 0.47 \\
\hline
\end{tabular}

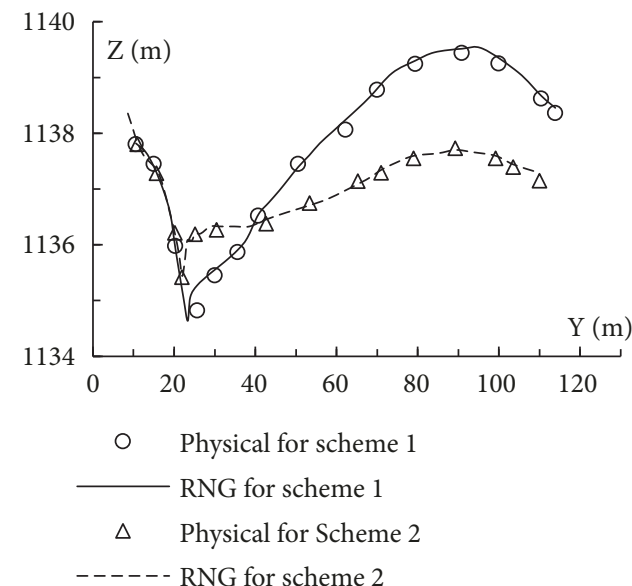

(a) Condition 1

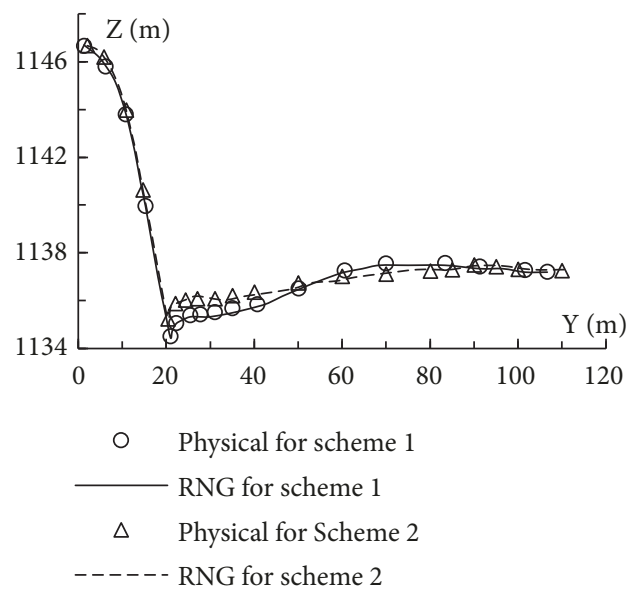

(b) Condition 2

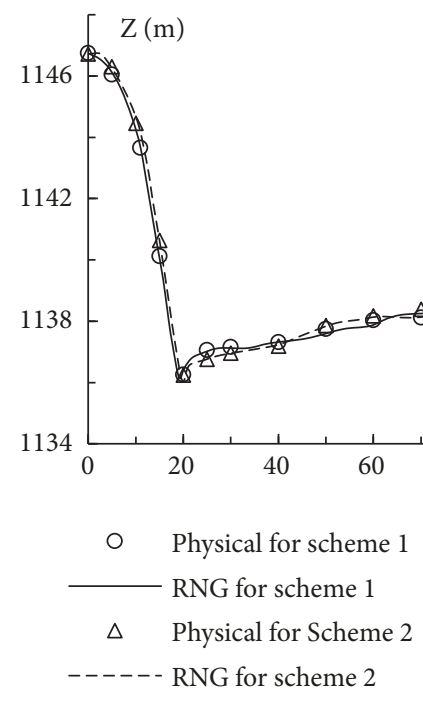

(c) Condition 3

FIGURE 10: Longitudinal water level distribution.

upstream and downstream sections, is mainly adopted to weigh the actual energy dissipation effect among the flow in the stilling basin. Energy dissipation rates for each condition are shown in Table 12. The potential energy is measured with reference to the downstream riverbed $(Z=1130 \mathrm{~m})$. The chosen upstream and downstream sections are, respectively, located at the inflow section $(\mathrm{Y}=-10 \mathrm{~m})$ and outgoing flow section
$(\mathrm{Y}=105 \mathrm{~m})$. It can be noticed that energy dissipation rates in all conditions are higher than $40 \%$ and much close to each other between both schemes, especially for the Condition 2 and Condition 3. The main reason depends on the compositions of total head-the potential energy and the velocity head. The potential energy depends on the water depth and the velocity head mainly depends on the average velocity of flow. 
In view of the relatively low values of outgoing flow average velocity, the potential energy accounts for larger proportions among the total head and the velocity head only accounts for fewer proportions. Such situation is quite common among the deep tailwater projects. In view of the close reservoir inflow between both schemes, the downstream tailwater would not change greatly in Condition 2 and Condition 3 even though average velocities of outgoing flow differ sharply. But compared to the separated stilling basin, the lateral cross section in the stilling basin for Condition 1 is enlarged almost three times in the compound stilling basin, thus greatly decreasing the downstream water level and necessarily resulting in some great influence upon energy dissipation rates. Observing the details in Table 11, the average velocities of outgoing flow in the compound stilling basin scheme only reaches $1.74 \mathrm{~m} / \mathrm{s}, 1.45 \mathrm{~m} / \mathrm{s}$, and $2.49 \mathrm{~m} / \mathrm{s}$ in three conditions, respectively, $64.1 \%, 30.0 \%$, and $22.9 \%$ lower than that of the separated stilling basin schemes.

\section{Conclusion}

Experimental and numerical investigations are conducted to show the influence of splitter wall upon the downstream stilling basin. Among the computed results from four kinds of turbulence models, the renormalization group k- $\varepsilon$ (RNG) turbulence model shows the most successful agreement with the experimental data.

In view of the removed splitter wall, discharging flow from the bottom outlet in Condition 1 (or surface outlet in Condition 2) would greatly diffuse to cover the whole compound stilling basin, thus resulting in large-scale reverse flow in the upstream region of the stilling basin. Similarly, in view of structure differences between both kinds of outlets, there would form velocity gradients among discharging inflow from adjacent outlets in Condition 3, thus inducing mutual impingement and shear friction between nearby flow. Due to the slightly moved upstream energy dissipation region in all conditions, the outgoing flow becomes much uniform in the compound stilling basin with the phenomenon of oblique movements being eliminated.

In general, compared to the separated stilling basin scheme, the hydraulic jump length in the compound stilling basin scheme reaches about 1.2-1.6 times longer; the mainstream depth decrease as low as 0.65 ; the maximum velocity and average velocity of the outgoing flow, respectively, drop more than $30 \%$ and $20 \%$. In addition, the velocity gradients between the left and the right outgoing flow decreases over $65 \%$ with turbulent kinetic energy gradients almost down to zero.

\section{Data Availability}

The all data used to support the findings of this study are included within the article.

\section{Conflicts of Interest}

The authors declare that they have no conflicts of interest.

\section{Acknowledgments}

This work was funded by National Natural Science Foundation of China (no. 51479145).

\section{References}

[1] B. M. Savage and M. C. Johnson, "Flow over ogee spillway: physical and numerical model case study," Journal of Hydraulic Engineering, vol. 127, no. 8, pp. 640-649, 2001.

[2] E. Kordi and I. Abustan, "Transitional expanding hydraulic jump," Journal of Hydraulic Engineering, vol. 138, no. 1, pp. 105$110,2012$.

[3] A. I. Stamou, D. G. Chapsas, and G. C. Christodoulou, "3D numerical modeling of supercritical flow in gradual expansions," Journal of Hydraulic Research, vol. 46, no. 3, pp. 402-409, 2008.

[4] A. Habibzadeh, M. R. Loewen, and N. Rajaratnam, "Mean flow in a submerged hydraulic jump with baffle blocks," Journal of Engineering Mechanics, vol. 140, no. 5, Article ID 04014020, pp. $1-15,2014$.

[5] R. Bremen and W. H. Hager, "T-jump in abruptly expanding channel," Journal of Hydraulic Research, vol. 31, no. 1, pp. 61-78, 2010.

[6] M. H. Omid, M. Esmaeeli Varaki, and R. Narayanan, "Gradually expanding hydraulic jump in a trapezoidal channel," Journal of Hydraulic Research, vol. 45, no. 4, pp. 512-518, 2007.

[7] A. R. Scorzini, M. Di Bacco, and M. Leopardi, "Experimental investigation on a system of crossbeams as energy dissipator in abruptly expanding channels," Journal of Hydraulic Engineering, vol. 142, no. 2, pp. 06015018-1-06015018-7, 2016.

[8] A. Kumar, "Mean flow characteristics of a turbulent dual jet consisting of a plane wall jet and a parallel offset jet," Computers \& Fluids, vol. 114, pp. 48-65, 2015.

[9] J. Chen, Y. Liao, and S. Liu, "Energy dissipation of hydraulic jump in gradually expanding channel after free overfall," Journal of the Chinese Institute of Engineers, vol. 36, no. 4, pp. 452-457, 2013.

[10] M. Bijankhan and S. Kouchakzadeh, "Free hydraulic jump due to parallel jets," Journal of Irrigation and Drainage Engineering, vol. 141, no. 2, pp. 04014049-1-04014049-9, 2015.

[11] M. Esmaeili Varaki, A. Kasi, J. Farhoudi, and D. Sen, "Hydraulic jump in a diverging channel with an adverse slope," Iranian Journal of Science and Technology - Transactions of Civil Engineering, vol. 38, no. 1, pp. 111-121, 2014.

[12] N. Hassanpour, A. Hosseinzadeh Dalir, D. Farsadizadeh, and C. Gualtieri, "An experimental study of hydraulic jump in a gradually expanding rectangular stilling basin with roughened bed," Water, vol. 9, no. 12, pp. 945-968, 2017.

[13] J. Zhang, W. Xu, P. Lin, and Y. Wang, "Briefing: Hydraulic jump in arbitrary prismatic channel," Proceedings of the Institution of Civil Engineers - Water Management, vol. 165, no. 3, pp. 141-145, 2012.

[14] Y. Ma, D. Z. Zhu, N. Rajaratnam, and B. van Duin, "Energy dissipation in circular drop manholes," Journal of Irrigation and Drainage Engineering, vol. 143, no. 12, pp. 04017047-1-0401704710, 2017.

[15] B. E. Launder and D. B. Spalding, Lectures in Mathematical Models of Turbulence, Academic, New York, NY, USA, 1972.

[16] V. Yakhot, S. A. Orszag, S. Thangam, T. B. Gatski, and C. G. Speziale, "Development of turbulence models for shear flows by 
a double expansion technique," Physics of Fluids, vol. 4, no. 7, pp. 1510-1520, 1992.

[17] T.-H. Shih, W. W. Liou, A. Shabbir, Z. Yang, and J. Zhu, "A new $\mathrm{k}-\varepsilon$ eddy viscosity model for high reynolds number turbulent flows," Computers \& Fluids, vol. 24, no. 3, pp. 227-238, 1995.

[18] C. Meneveau, T. S. Lund, and W. H. Cabot, "A Lagrangian dynamic subgrid-scale model of turbulence," Journal of Fluid Mechanics, vol. 319, pp. 353-385, 1996.

[19] D. Valero, D. B. Bung, and B. M. Crookston, "Energy dissipation of a type III basin under design and adverse conditions for stepped and smooth spillways," Journal of Hydraulic Engineering, vol. 144, no. 7, pp. 04018036-1-04018036-10, 2018.

[20] V. Gumus, O. Simsek, N. G. Soydan, and M. S. Akoz, "Numerical modeling of submerged hydraulic jump from a sluice gate," Journal of Irrigation and Drainage Engineering, vol. 142, no. 1, pp. 04015037-1-04015037-11, 2016.

[21] M. García Pérez and E. Vakkilainen, "A comparison of turbulence models and two and three dimensional meshes for unsteady CFD ash deposition tools," Fuel, vol. 237, pp. 806-811, 2019.

[22] B. E. Launder and D. B. Spalding, "The numerical computation of turbulent flows," Computer Methods Applied Mechanics and Engineering, vol. 3, no. 2, pp. 269-289, 1974.

[23] M. S. Kirkgöz and M. Ardiçlioǧlu, "Velocity profiles of developing and developed open channel flow," Journal of Hydraulic Engineering, vol. 123, no. 12, pp. 1099-1106, 1997.

[24] L. Cassan and G. Belaud, "Experimental and numerical investigation of flow under sluice gates," Journal of Hydraulic Engineering, vol. 138, no. 4, pp. 367-373, 2012.

[25] S. Muzaferija and M. Perić, "Computation of free-surface flows using the finite-volume method and moving grids," Numerical Heat Transfer, Part B: Fundamentals, vol. 32, no. 4, pp. 369-384, 1997.

[26] C. W. Hirt and B. D. Nichols, "Volume of fluid method for the dynamics of free boundaries," Journal of Computational Physics, vol. 39, no. 1, pp. 201-225, 1981.

[27] S. Haun, N. R. Olsen, and R. Feurich, "Numerical modeling of flow over trapezoidal broad-crested weir," Engineering Applications of Computational Fluid Mechanics, vol. 5, no. 3, pp. 397405, 2011.

[28] P. J. Roache, "Quantification of uncertainty in computational fluid dynamics," Annual Review of Fluid Mechanics, vol. 29, pp. 123-160, 1997.

[29] I. B. Celik, U. Ghia, P. J. Roache, C. J. Freitas, H. Coleman, and P. E. Raad, "Procedure for estimation and reporting of uncertainty due to discretization in CFD applications," Journal of Fluids Engineering, vol. 130, no. 1, pp. 1-4, 2008.

[30] M. S. Kirkgöz, M. S. Aköz, and A. A. Öner, "Numerical modeling of flow over a chute spillway," Journal of Hydraulic Research, vol. 47, no. 6, pp. 790-797, 2009. 


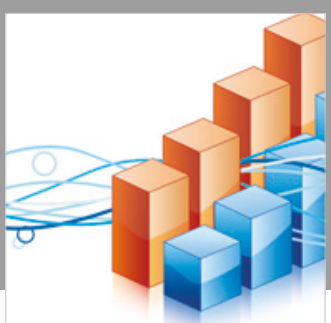

Advances in

Operations Research

\section{-n-m}
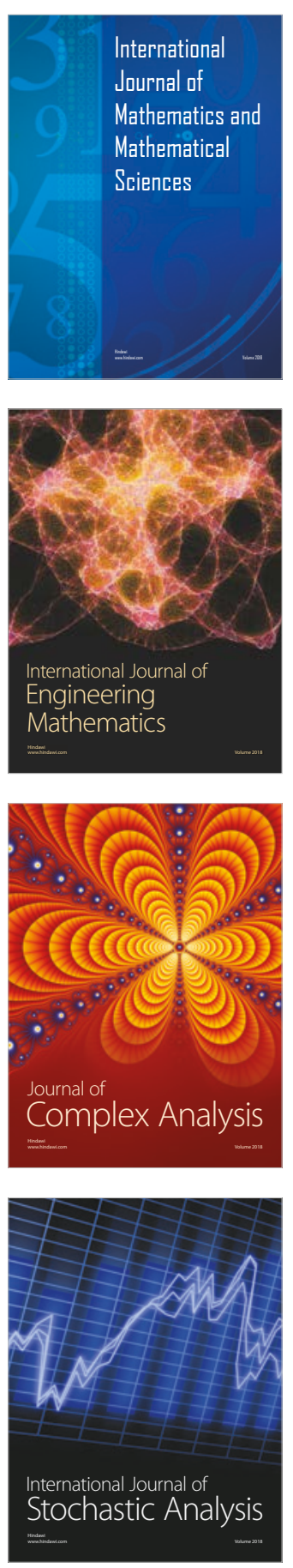
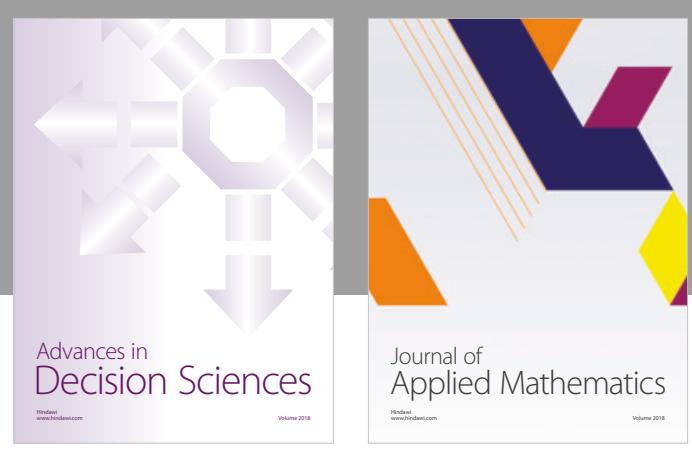

Journal of

Applied Mathematics
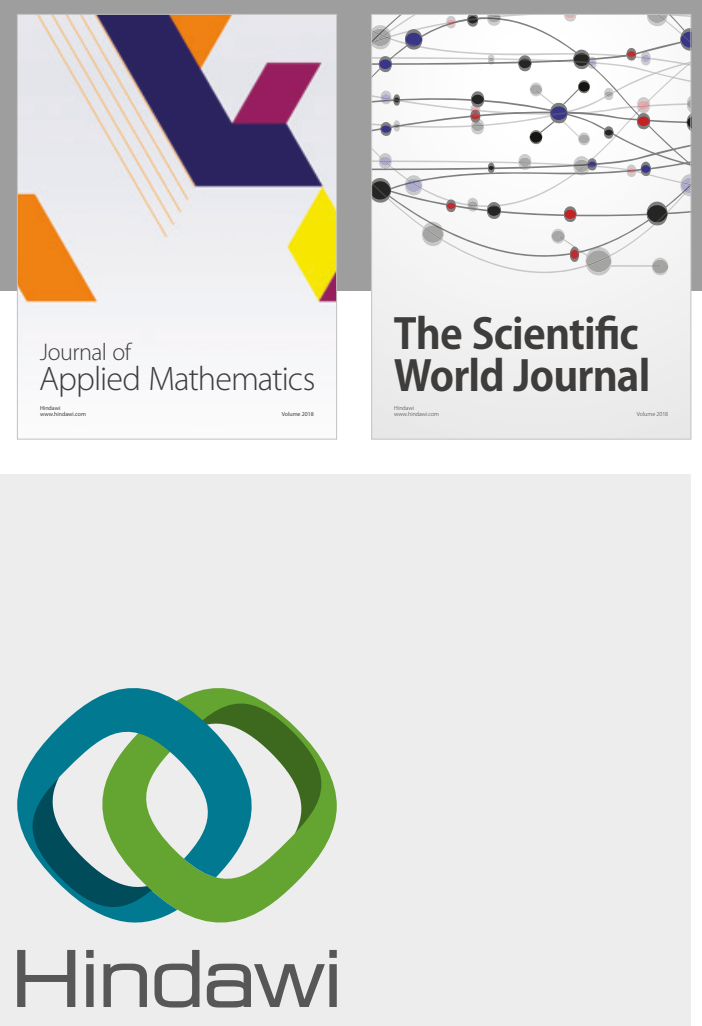

Submit your manuscripts at

www.hindawi.com

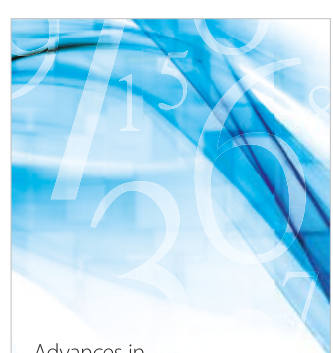

Advances in
Numerical Analysis
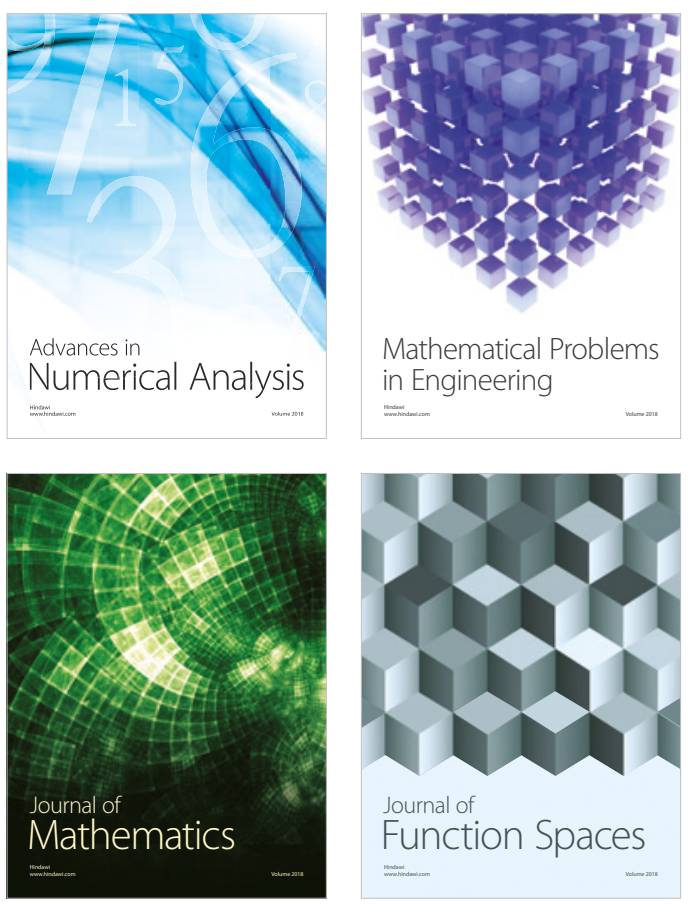

Mathematical Problems in Engineering

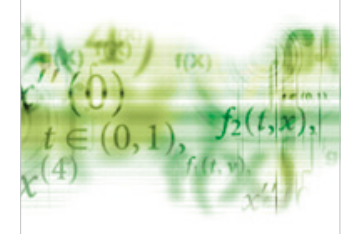

International Journal of

Differential Equations

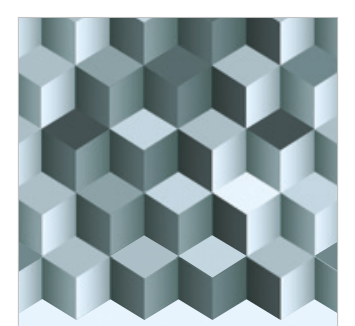

Journal of

Function Spaces

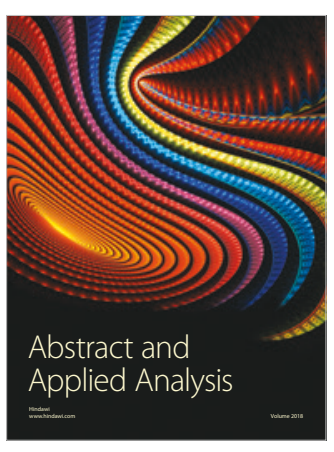

The Scientific

World Journal

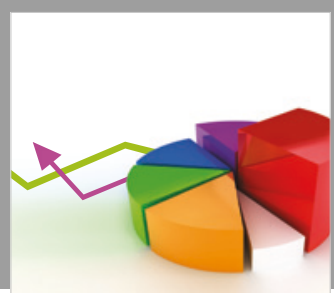

Journal of

Probability and Statistics
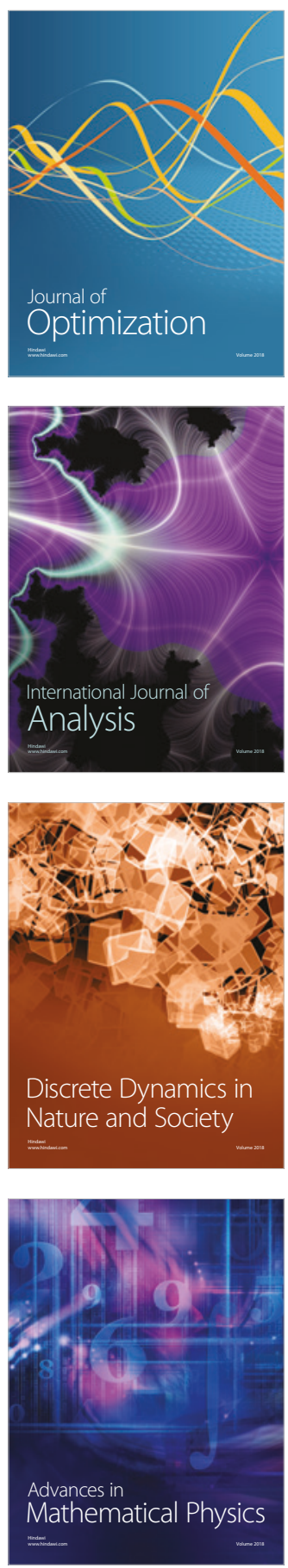